\title{
Allelic Variants of the Pseudomonas syringae Type III Effector HopZ1 Are Differentially Recognized by Plant Resistance Systems
}

\author{
Huanbin Zhou, ${ }^{1}$ Robyn L. Morgan, ${ }^{1}$ David S. Guttman, ${ }^{2}$ and Wenbo Ma ${ }^{1}$ \\ ${ }^{1}$ Department of Plant Pathology and Microbiology, University of California, Riverside 92521, U.S.A.; ${ }^{2}$ Centre for the Analysis \\ of Genome Evolution and Function, University of Toronto, Toronto, Ontario M5S3B2, Canada
}

Submitted 14 March 2008. Accepted 10 October 2008.

\begin{abstract}
The bacterial plant pathogen Pseudomonas syringae depends on the type III secretion system and type III-secreted effectors to cause disease in plants. HopZ is a diverse family of type III effectors widely distributed in $P$. syringae isolates. Among the HopZ homologs, HopZ1 is ancient to $P$. syringae and has been shown to be under strong positive selection driven by plant resistance-imposed selective pressure. Here, we characterized the virulence and avirulence functions of the three HopZ1 alleles in soybean and Nicotiana benthamiana. In soybean, HopZ1 alleles have distinct functions: HopZ1a triggers defense response, HopZ1b promotes bacterial growth, and HopZ1c has no observable effect. In $N$. benthamiana, HopZ1a and HopZ1b both induce plant defense responses. However, they appear to trigger different resistance pathways, evidenced by two major differences between HopZ1a- and HopZ1b-triggered hypersensitive response (HR): i) the putative $\mathrm{N}$-acylation sites had no effect on HopZ1a-triggered cell death, whereas it greatly enhanced HopZ1b-triggered cell death; and ii) the HopZ1b-triggered HR, but not the HopZ1a-triggered HR, was suppressed by another HopZ homolog, Hopz3. We previously demonstrated that HopZ1a most resembled the ancestral allelic form of HopZ1; therefore, this new evidence suggested that differentiated resistance systems have evolved in plant hosts to adapt to HopZ1 diversification in $P$. syringae.
\end{abstract}

Additional keywords: co-evolutionary arms race, myristoylation, palmitoylation.

Dynamics of plant-pathogen interactions are determined by a co-evolutionary arms race between the antagonistic partners, in which the pathogens and the hosts impose reciprocal selection pressures on each other, leading to the evolution of increasingly effective attack and counter-attack strategies (Dawkins and Krebs 1979; Stahl and Bishop 2000). One of the key pathogenicity determinants in bacterial pathogens is the type III secretion system (T3SS), which is widespread and highly conserved in a broad range of gram-negative bacterial pathogens responsible for some of the most devastating diseases on animals and plants (Alfano and Collmer 1997, 2004; He et al. 2004). The T3SS is a specialized protein secretion

Corresponding author: Wenbo Ma; Telephone: +1 (951) 827-4349; Fax: +1 (951) 827-4294; E-mail: wenbo.ma@ucr.edu

* The $\boldsymbol{e}$-Xtra logo stands for "electronic extra" and indicates a supplementary figure is published online. apparatus that penetrates the host cell membrane and injects type III-secreted effectors (T3SEs) directly into the host cell cytosol. T3SEs target host substrates, especially those involved in plant defense pathways, and play an essential role in bacterial infection and disease development (Alfano and Collmer 2004). Adapting to pathogen attack through T3SEs, plants evolved resistance $(\mathrm{R})$ proteins that recognize specific T3SEs, either directly or indirectly (Chisholm et al. 2006; Dangl and Jones 2001; Van der Hoorn et al. 2002). Recognition of T3SEs by plant $\mathrm{R}$ proteins triggers defense responses, which are usually associated with a rapid and localized programmed cell death called the hypersensitive response (HR) (Greenberg 1997; Heath 2000). These T3SEs are then designated avirulence (Avr) proteins. Plant $R$ genes impose intensive selection pressures on the pathogens to evade recognition by either altering or inactivating the Avr proteins in order to regain the ability to infect their hosts (Herbers 1992; Pitman et al. 2005; Sokurenko et al. 1999). In the cases when the functions of the Avr proteins are important for virulence (i.e., inactivation of these genes would cause a significant reduction on the pathogen fitness), pathogens could overcome the host resistance by sequence variation which maintains a conserved virulence function while, at the same time, evading detection (Dodds et al. 2006; McCann and Guttman 2008; Robertson et al. 2004; Sokurenko et al. 1998). Positive and diversifying selection of pathogen effectors have been shown in bacteria (Guttman et al. 2006; Ma et al. 2006; Rohmer et al. 2004), oomycetes (Allen et al. 2004; Win et al. 2007), and fungal pathogens (Dodds et al. 2006). However, very few examples have experimentally demonstrated the parallel genetic diversification of pathogen virulence factors and the corresponding host $R$ genes. One such example is from Dodds and associates (2006), who very elegantly showed that the diversification of both the AvrL567 gene of the flax rust fungus (Melampsora lini) and its corresponding L locus in flax was resulted from R-Avr counterselection.

The plant pathogen Pseudomonas syringae has emerged as a model organism to study bacterial pathogen-plant interactions. $P$. syringae secretes approximately 50 effector families through its T3SS (Grant et al. 2006). One of the most diverse and widespread T3SE families is the HopZ family, whose members are homologs of YopJ from Yersinia spp. Originally classified as a cysteine protease, YopJ has recently been shown to act as an acetyltransferase, which inhibits mitogen-activated protein kinase (MAPK) and the nuclear factor $\kappa \mathrm{B}$ signaling pathways in mammalian immune systems by directly blocking the phosphorylation of serine and threonine residues in MAPKK6 (Mukherjee et al. 2006). YopJ homologs have been 
identified in many bacterial pathogens infecting both animals and plants, thus implying a fundamentally important role of these effectors in disease development (Hotson and Mudgett 2004; Orth et al. 1999). So far, three YopJ homologs, HopZ1, HopZ2, and HopZ3, have been identified from P. syringae (Arnold et al. 2001; Charity et al. 2003; Deng et al. 2003; Guttman et al. 2002; Lindeberg et al. 2005; Ma et al. 2006; Sundin et al. 2004). Furthermore, three functional allelic groups or subfamilies of HopZ1-HopZ1a, HopZ1b, and HopZ1c-were identified (Ma et al. 2006).

A survey of $96 P$. syringae strains isolated from a variety of plant hosts worldwide revealed that $42 \%$ of these strains produce a functional HopZ T3SE. Evolutionary analysis demonstrated that HopZ1, ancient to $P$. syringae, was under strong positive selection, and that one of the allelic variants, HopZ1a, most resembled the ancestral allelic form. Exogenous HopZ1a expressed in $P$. syringae strains carrying other HopZ alleles triggered defense responses in plants susceptible to the wildtype pathogens (Ma et al. 2006). For example, HopZ1 $\mathrm{a}_{\mathrm{PsyA} 2}$ (HopZ1a hereafter) caused an HR on soybean and Arabidopsis thaliana. These are compatible hosts of $P$. syringae pv. glycinea and $P$. syringae pv. maculicola ES4326, which produces

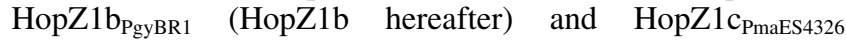
(HopZ1c hereafter), respectively. Considering the information from the evolutionary and functional analyses together, it appears that HopZ1 and its corresponding plant $\mathrm{R}$ proteins are engaged in a co-evolutionary arms race (Ma et al. 2006). A recent study from Lewis and associates (2008) further investigated the function of the HopZ homologs in Arabidopsis. The authors demonstrated that a potential N-terminal myristoylation site was important for the virulence function of HopZ2 and the avirulence function of HopZ1a in Arabidopsis.

In this study, we characterized the virulence and avirulence functions of the three HopZ1 alleles in soybean and Nicotiana benthamiana in an attempt to further understand the molecular basis underlying this co-evolutionary arms race. Soybean is a natural host of $P$. syringae pv. glycinea strains, which all produce functional HopZ1b. Furthermore, HopZ1b appears to be exclusively produced by these soybean pathogens (Ma et al. 2006). Using soybean and $N$. benthamiana as hosts, we were able to demonstrate the distinct functions of these closely related allelic variants. In soybean, HopZ1b promotes bacterial growth whereas HopZ1a triggers defense responses. Furthermore, the putative $\mathrm{N}$-terminal myristoylation motif is required for the avirulence function of HopZ1a in soybean, similar to what has been shown in Arabidopsis (Lewis et al. 2008). However, it does not appear to be important for the virulence function of HopZ1b. In N. benthamiana, HopZ1a and HopZ1b both trigger HR-like cell death but they seem to be recognized by differentiated plant resistance pathways. This new evidence supports our hypothesis that $N$. benthamiana evolved a new or modified defense mechanism to recognize HopZ1b as a counter-adaptation step to match the diversified HopZ1b, an allelic variant of a HopZ1a-like ancestor during the co-evolutionary arms race.

\section{RESULTS}

\section{Effect of HopZ1 on bacterial growth in soybean.}

In a previous study, we demonstrated that HopZ1a caused HR in soybean, whereas HopZ1b did not trigger defense responses despite the overall high sequence similarity $(72 \%$ identity, $81 \%$ similarity) between these two allelic variants (Ma et al. 2006). HopZ1b appears to be exclusively produced by $P$. syringae pv. glycinea strains that were isolated from soybean. All tested $P$. syringae pv. glycinea strains, including strain BR1 (PgyBR1), have nearly identical DNA sequences in their housekeeping genes and hopZ1b gene (Ma et al. 2006; Sarkar and Guttman 2004). In addition, the P. syringae pv. glycinea strains all grow to a similar level in soybean (data not shown). We generated a rifampicin resistance strain of $P g y$ BR 1 in order to track bacterial multiplication in planta. This strain, designated PgyBR1Rif, multiplied to the same level as $P g y$ BR1 in soybean (data not shown) and was used as the wild-type strain for all our experiments.

In order to characterize the functions of HopZ1 alleles in soybean, we constructed a T3SS knock-out mutant PgyBR1Rif::

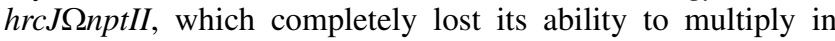
soybean, confirming that the T3SS and T3SEs were indispensable for $P$. syringae pv. glycinea strains to infect soybean (Fig. 1A). In an attempt to make a HopZ1b loss-of-function mutant, we first employed the double homologous recombination approach. However, after numerous trials using a variety of plasmid vectors, we could not obtain such a mutant. We then employed an indirect approach and made the mutant PgyBR1Rif-O1 by curing the plasmid pPgyBR1a, an endogenous plasmid (approximately $90 \mathrm{~kb}$ ) carrying hopZlb, using acridine orange as the mutagen. PgyBR1Rif-O1 showed a significant growth reduction (approximately 10-fold) in soybean compared with that of the wild-type strain (Fig. 1A). However, the reduction in bacterial multiplication could not be restored in PgyBR1Rif-O1 expressing HopZ1b carried on pUCP20tk (Fig. 1B). This was not due to the lack of HopZ1b protein expression according to our Western blot analysis (Fig. 1D).

We also introduced the other two HopZ1 alleles, HopZ1a and HopZ1c, into PgyBR1Rif-O1 to examine their function in bacterial growth in soybean. We used $P g y$ BR1Rif-O1 rather than $P g y$ BR1Rif in order to eliminate any possible interference between HopZ1b and other HopZ1 alleles either inside the bacteria cells or in planta due to their high sequence similarity. Our growth assay showed an approximately 15 -fold reduction in the bacteria growth of PgyBR1Rif-O1 expressing HopZ1a compared with that of PgyBR1Rif-O1 (Fig. 1B). This is consistent with the previous data showing the cell death-eliciting activity of HopZ1a in soybean (Ma et al. 2006). PgyBR1RifO1 expressing HopZ1c multiplied to the same level in soybean as the parental strain (Fig. 1B).

We next tested whether HopZ1b confers a growth advantage to $P$. syringae strains that are not pathogens to soybean. We used $P$. syringae pv. phaseolicola 1302A (Pph1302A), a pathogen of kidney beans, as a nonhost pathogen of soybean. Although $P$. syringae pv. phaseolicola strains are the closest relatives of $P$. syringae pv. glycinea strains according to the coregenome phylogeny (Sarkar and Guttman 2004), none of the $P$. syringae pv. phaseolicola strains produce any known HopZ family effectors (Ma et al. 2006). Moreover, bacterial in planta multiplication assays showed that the populations of $P$. syringae pv. phaseolicola strains in soybean were at least 10- to 1,000 -fold lower than that of the $P$. syringae pv. glycinea strains 6 days postinoculation (data not shown). We introduced the plasmid pUCP20tk::HopZ1b-HA into Pph1302ARif, a rifampicin resistance mutant of $P p h 1302 \mathrm{~A}$. Bacterial multiplication assays demonstrated that Pph1302ARif expressing HopZ1b reached a population of approximately fivefold higher in soybean than that of the parental strain Pph1302ARif or Pph1302ARif carrying the empty vector (Fig. 2A).

\section{Catalytic core is required for HopZ1 function in soybean.}

YopJ homologs have conserved catalytic cores consisting of a histidine $(\mathrm{H})$, a glutamic acid $(\mathrm{E})$, and a cysteine $(\mathrm{C})$ (Barrett and Rawlings 2001; Orth et al. 2000). Cysteine216 (Cys216) and cysteine212 (Cys212) are the key cysteine residues in the predicted catalytic cores of HopZ1a and HopZ1b, respectively. In vitro protease assays using a generic substrate have shown 
that Cys216 is required for the protease activity of HopZ1a (Ma et al. 2006). In order to examine whether the enzymatic activity is required for HopZ1a to trigger defense responses as well as for HopZ1b to promote bacterial growth in soybean, we generated mutants with the Cys216 in HopZ1a and the Cys212 in HopZ1b replaced with alanines. The mutant genes encoding HopZ1a(C216A) and HopZ1b(C212A) were ligated into pUCP20tk with their native promoters and introduced into $P g y$ BR1Rif-O1 and Pph1302Arif, respectively.

Bacterial growth assay showed that PgyBR1Rif-O1 expressing HopZ1a(C216A) grew to the same level as that of PgyBR1Rif-O1 carrying the empty vector, suggesting that the key catalytic cysteine residue was required for HopZ1a to trigger defense responses in soybean (Fig. 1B). To confirm the loss of HR-eliciting activity of HopZ1a(C216A), we infiltrated soybean leaves with PgyBR1Rif-O1 expressing HopZ1a or HopZ1a(C216A). Our results clearly demonstrated that HopZ1a(C216A) no longer elicited HR in soybean (Fig. 1C).

We also examined whether HopZ1b(C212A) lost the bacterial growth-promoting activity in soybean. Pph1302ARif expressing
HopZ1b(C212A) grew to the same level as the parental strain (Fig. 2A), suggesting that HopZ1b required the predicted catalytic cysteine residue for its virulence function.

\section{The potential N-terminal myristoylation site} of HopZ1a contributes to its avirulence function in soybean.

Several YopJ family T3SEs contain putative myristoylation motifs in their N-terminal sequences (Lewis et al. 2008; Thieme et al. 2007). Myristoylation is a eukaryotic-specific post-translational modification that usually directs proteins to biological membranes by covalently attaching a 14-carbon myristoyl lipid anchor to an N-terminal glycine residue (usually in the second position) of the protein (Maurer-Stroh and Eisenhaber 2004; Resh 1999). HopZ1 all contain the consensus sequence (MGNIC) in the N-termini for fatty acylations, with the glycine in the second position (Gly2) being a potential myristoylation site. It has been shown that HopZ1 is localized to the cellular membranes and that Gly 2 is required for the avirulence function of HopZ1a in Arabidopsis (Lewis et al. 2008).
A

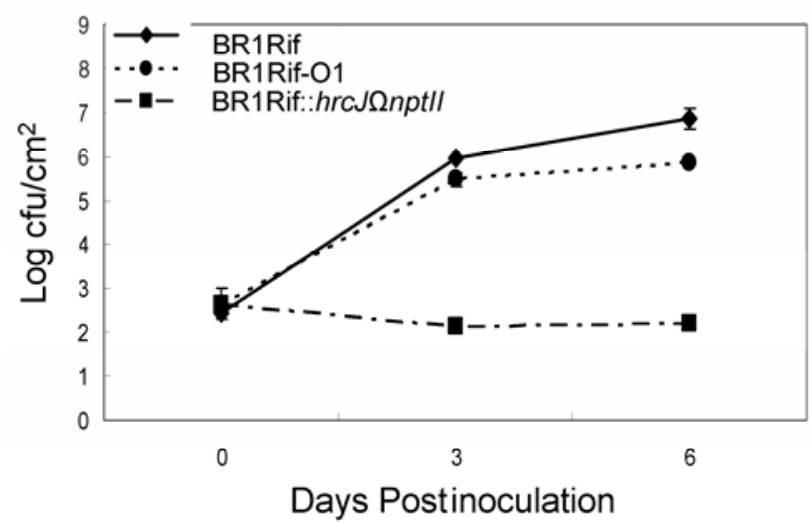

C

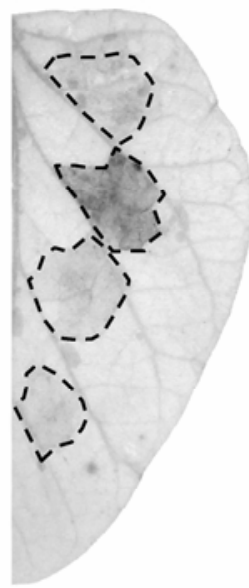

vector

Z1a

$\mathrm{Z1a}(\mathrm{G} 2 \mathrm{~A})$

$\mathrm{Z1a}(\mathrm{C} 216 \mathrm{~A})$
B

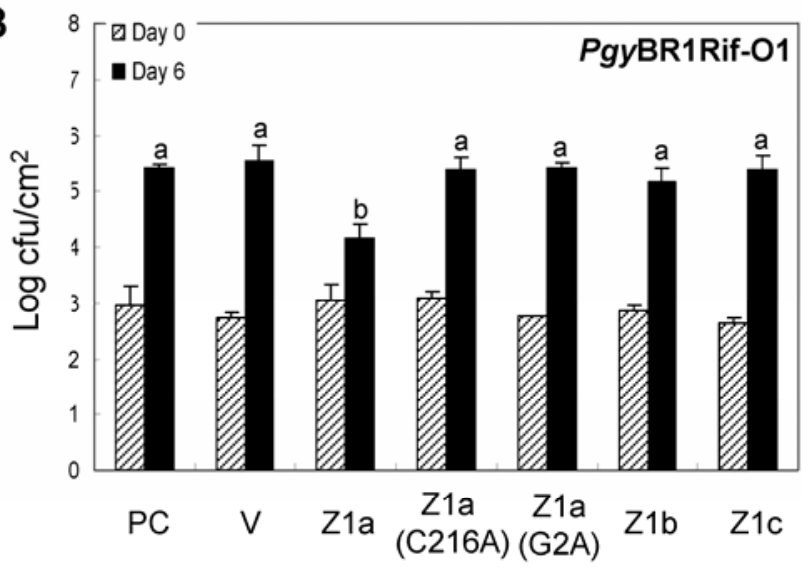

D

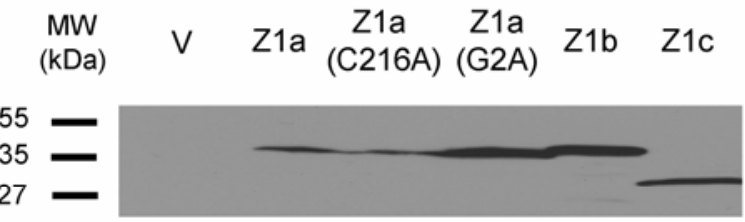

Fig. 1. Effect of HopZ1 on bacterial growth of Pseudomonas syringae pv. glycinea in soybean. A, Bacterial in planta multiplication of the wild-type strain $P g y B R 1 R i f$, the plasmid-cured mutant PgyBR1Rif-O1, and the type III secretion system knock-out mutant PgyBR1Rif::hrcJ $2 n p t I I$. Bacterial cell suspensions (optical density at $600 \mathrm{~nm}\left[\mathrm{OD}_{600}\right]=0.2$ ) were sprayed on the unifoliates of 9-day old soybean and the bacterial populations were presented by counting CFU per square centimeter 0, 3, and 6 days postinoculation (dpi). B, Bacterial in planta multiplication of the plasmid-cured strain PgyBR1Rif-O1 (PC) expressing HopZ1a, HopZ1a(C216A), HopZ1a(G2A), HopZ1b, and HopZ1c carried on the plasmid vector pUCP20tk. The empty pUCP20tk vector (V) was used as a control. Bacterial populations were determined 0 and 6 dpi. Each value represents the mean of bacterial populations in four leaves from four different plants. Error bars represent the standard errors. Values that are statistically different are labeled with different letters. All experiments were repeated three times and the data from one experiment are presented. C, HopZ1a-triggered hypersensitive response (HR) in soybean requires the catalytic cysteine residue and a potential N-terminal myristoylation site. Unifoliates of 14-day-old soybean plants were pressure infiltrated with PgyBR1Rif-O1 expressing HopZ1a, HopZ1a(G2A), and HopZ1a(C216A) at $\mathrm{OD}_{600}=0.5$. The empty pUCP20tk vector $(\mathrm{V})$ was used as a control. Soybean leaves were harvested 48 h postinoculation (hpi) and photographed after bleaching with 95\% ethanol. D, Immunoblot showing the wild-type and mutant HopZ1 protein expression in PgyBR1RifO1. PgyBR1Rif-O1 cells expressing HopZ1 proteins were induced in M63 minimal medium containing 1\% fructose overnight at room temperature. Total bacterial proteins from $1 \mathrm{ml}$ of the induced cells were extracted and HopZ1 proteins were detected by anti-hemagglutinin antibody conjugated with horseradish peroxidase. 
To examine whether the potential myristoylation motif plays a role in the avirulence function of HopZ1a and the virulence function of HopZ1b in soybean, the mutants HopZ1a(G2A) and HopZ1b(G2A) were constructed with the Gly2 replaced with an alanine. We then expressed HopZ1a $(G 2 A)$ in PgyBR1Rif-O1 and HopZ1b(G2A) in Pph1302ARif. Their functions in triggering defense responses and promoting nonhost pathogen multiplication in soybean, respectively, were examined and compared with those of the wild-type proteins. HR assays showed that HopZ1a(G2A) completely abolished the HR-eliciting activity of HopZ1a in soybean (Fig. 1C). Consistent with the HR assays, PgyBR1Rif-O1 expressing HopZ1a(G2A) multiplied to the same level as that of PgyBR1Rif-O1(pUCP20tk) or PgyBR1Rif-O1 (pUCP20tk:: HopZ1a (C216A)), suggesting that the avirulence activity of HopZ1a required the potential myristoylation site (Fig. 1B).

Bacterial in planta multiplication assays showed that Pph1302ARif expressing HopZ1b(G2A) grew to the same level in soybean as Pph1302ARif expressing the wild-type HopZ1b, indicating that HopZ1b(G2A) conferred a growth advantage to Pph1302ARif similar to the wild-type HopZ1b. These data suggested that the potential myristoylation site was not required for the virulence function of HopZ1b (Fig. 2A).

The wild type and the G2A mutant of HopZ1 proteins were also fused in-frame to yellow fluorescent protein (YFP) at the C-termini in the plasmid pAVA319 (von Arnim et al. 1998). The localization of these proteins, transiently expressed in onion epidermal cells, was examined using confocal laser scanning microscopy. The wild-type HopZ1-YFP fusion proteins were exclusively localized to the plasma membrane, whereas HopZ1(G2A)-YFP fusion proteins were present mostly in the cytoplasm (Supplementary Fig. 1). These data confirmed that the potential myristoylation sites in HopZ1 were important for their membrane localization in plant cells.

\section{Characterization of HopZ1-triggered plant responses in $N$. benthamiana.}

When transiently expressed in $N$. benthamiana through Agrobacterium infiltration, HopZ1a and HopZ1b induced an HR-like cell death but HopZ1c did not (Ma et al. 2006). However, we noticed that the cell death phenotypes elicited by HopZ1a and HopZ1b were different. At an optical density at $600 \mathrm{~nm}\left(\mathrm{OD}_{600}\right)=0.1$, HopZ1b triggered a strong HR-like cell death symptom that became visible approximately $36 \mathrm{~h}$ postinoculation (hpi), whereas HopZ1a-triggered cell death appeared approximately 48 to 60 hpi (Fig. 3A). Furthermore, the infiltrated leaf areas with Agrobacterium tumefaciens expressing HopZ1a showed a patchy yellow color but HopZ1b expression led to uniformly glossy areas representing strong cell death in the infiltrated $N$. benthamiana leaves.

It has been shown previously that the mutant HopZ1a(C216A) lost the ability to trigger HR-like cell death symptoms when it was transiently expressed in $N$. benthamiana (Ma et al. 2006). To determine whether the predicted catalytic cysteine residue was also required for HopZ1b to induce HR, we infiltrated $N$. benthamiana with A. tumefaciens carrying pMDD1::HopZ1b(C212A). Similar to HopZ1a(C216A), HopZ1b(C212A) completely lost the cell death-eliciting activity (Fig. 3A), suggesting that the catalytic cysteine residue and, most likely, the enzymatic activity was required for HopZ1b to trigger defense responses in $N$. benthamiana.

We then examined the role of the putative $\mathrm{N}$-myristoylation site of HopZ1a and HopZ1b in their cell-death-eliciting activity in $N$. benthamiana by transiently expressing HopZ1a(G2A) and HopZ1b(G2A) and examining their cell-death-eliciting activities. Interestingly, although the cell death symptom of HopZ1a(G2A) was indistinguishable from that of the wild- type HopZ1a, HopZ1b(G2A) displayed a much delayed and weaker cell death symptom compared with that triggered by the wild-type HopZ1b in N. benthamiana (Fig. 3B). The infiltrated area of HopZ1b(G2A) showed a patchy cell death symptom which became visible approximately $12 \mathrm{~h}$ later than that of HopZ1b, indicating a weaker and uneven development of an HR-like cell death.

Membrane localization directed by myristoylation can be enhanced by additional membrane-attachment factors, such as subsequent palmitoylation on a cysteine residue in close proximity to the myristoylated glycine residue by covalently attaching a palmitoyl lipid anchor to the cysteine (Resh 1999). Both HopZ1a and HopZ1b contain a cysteine residue at the fifth position (Cys5), which could be a potential palmitoylation site. To study the contribution of this putative palmitoylation site in HopZ1a- and HopZ1b-triggered cell death in $N$. benthamiana, we mutated Cys5 by replacing the residue with an alanine. HopZ1a(C5A) still elicited cell death in N. benthamiana, and the symptom was indistinguishable from that caused by HopZ1a or HopZ1a(G2A) (Fig. 3B). However, similarly to HopZ1b(G2A), HopZ1b(C5A) induced a weaker and delayed cell death compared with that of the wild-type HopZ1b (Fig. 3B).

To investigate the possibility that the putative myristoylation and palmitoylation work coordinately for HopZ1 to trigger $\mathrm{HR}$, we constructed the mutants, HopZ1a(G2AC5A) and

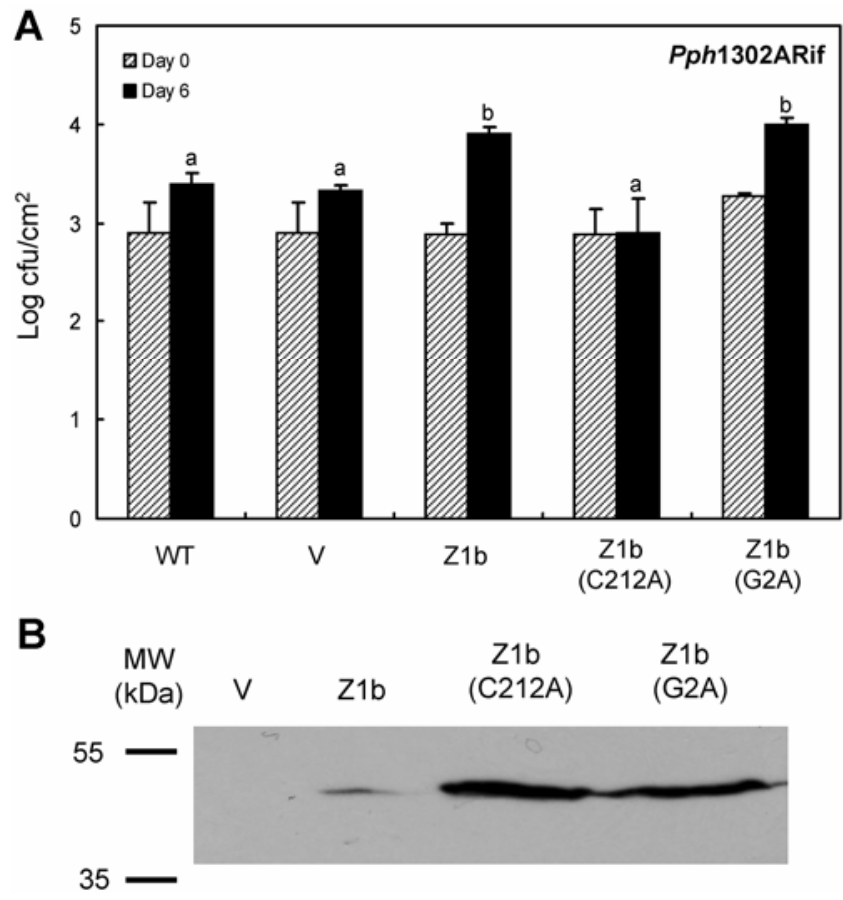

Fig. 2. Effect of HopZ1b on bacterial multiplication of Pseudomonas syringae pv. phaseolicola strain 1302ARif (Pph1302ARif) in soybean. Bacterial cell suspensions (optical density at $600 \mathrm{~nm}=0.2$ ) were sprayed on the unifoliates of 9-day-old soybean plants. Each value represents the mean of the bacterial populations in four leaves from four different plants. Error bars represent the standard errors. All experiments were repeated three times and the data from one experiment are presented. A, Bacterial in planta multiplication of Pph1302ARif (WT) expressing HopZ1b, $\mathrm{HopZ} 1 \mathrm{~b}(\mathrm{C} 212 \mathrm{~A})$ and $\mathrm{HopZ} 1 \mathrm{~b}(\mathrm{G} 2 \mathrm{~A})$ were determined 0 and 6 days postinoculation. The empty pUCP20tk vector (V) was used as a control. Values that are statistically different are labeled with different letters. B, Immunoblot showing the wild-type and mutant HopZ1b protein expression in Pph1302ARif. Bacterial cells were induced in M63 minimal medium containing $1 \%$ fructose overnight at room temperature. Total proteins were extracted from $1 \mathrm{ml}$ of the induced cells, and the hemagglutinin (HA)-tagged HopZ1b proteins were detected by anti-HA antibody conjugated with horseradish peroxidase. 
HopZ1b(G2AC5A), with both Gly2 and Cys5 replaced with alanine residues. Similar to HopZ1a(G2A), HopZ1a(G2AC5A) still triggered cell death in $N$. benthamiana and displayed a symptom that was indistinguishable from that of HopZ1a (Fig. 3B). In contrast, HopZ1b(G2AC5A) triggered an even weaker cell death symptom compared with that of $\operatorname{HopZ1b}(\mathrm{G} 2 \mathrm{~A})$ or HopZ1b(C5A) (Fig. 3B), suggesting that the putative myristoylation site and the putative palmitoylation site both contributed to HopZ1b-triggered cell death in N. benthamiana.

\section{HopZ1b-triggered HR can be suppressed by HopZ3.}

HopZ3 $3_{\text {PsyB728a }}$ (HopZ3 hereafter), a HopZ homolog, has been reported to be able to suppress the HR-like cell death elicited by AvrPto, HopAA1, HopM1, and HopAE1 in N. benthamiana (Vinatzer et al. 2006). In order to investigate whether HopZ3 could also interfere with the HR induced by HopZ1a or HopZ1b, N. benthamiana leaves were first infiltrated with $A$. tumefaciens harboring empty pMDD1 vector, pMDD1 carrying HopZ3, or pMDD1 carrying HopZ3(C300A). Cysteine300 is the predicted key cysteine residue in HopZ3 that is presumably required for its enzymatic activity. Four hours later, the same infiltrated areas were infiltrated again with $A$. tumefaciens harboring pMDD1 carrying HopZ1a or HopZ1b. N. benthamiana co-expressing HopZ3 and HopZ1a exhibited an HRlike cell death symptom, whereas leaf tissues co-expressing HopZ3 and HopZ1b lost the cell death symptom, suggesting that HopZ3 suppressed the HR-like cell death elicited by HopZ1b but did not interfere with that triggered by HopZ1a (Fig. 4A). This cell-death-interference activity is dependent on the Cys300 of HopZ3 because $N$. benthamiana leaves co-infiltrated with HopZ3(C300A) and HopZ1b still displayed a strong HR-like cell death symptom (Fig. 4A). It is likely that the enzymatic activity of HopZ3 is required for its HR suppression activity.

To further confirm that HopZ3 did interfere with the plant defense responses triggered by HopZ1b, we determined whether HopZ3 could inhibit the HopZ1b-induced pathogenesis-related (PR) gene PR-1a expression in $N$. benthamiana using real-time reverse-transcriptase polymerase chain reaction (RT-PCR). N. benthamiana leaf tissues transiently expressing different HopZ homologs or different combinations of these homologs were harvested 16 and 24 hpi. Total RNA was isolated from the leaf tissues and real-time RT-PCR was performed using the RNA samples as templates and primers recognizing $P R-1 a$ and $N t-A c t 9$ transcripts. Act 9 , constitutively expressed in $N$. benthamiana, was used as an internal quantitative control, and the number of $P R-1 a$ transcripts was normalized by the number of Nt-Act 9 transcripts in the same sample. The induction of $P R-1 a$ was represented by the fold increase of the normalized $P R-1 a$ transcripts in $N$. benthamiana leaves expressing HopZ effectors compared with that in leaves infiltrated with $A$. tumefaciens carrying the empty pMDD1 vector.
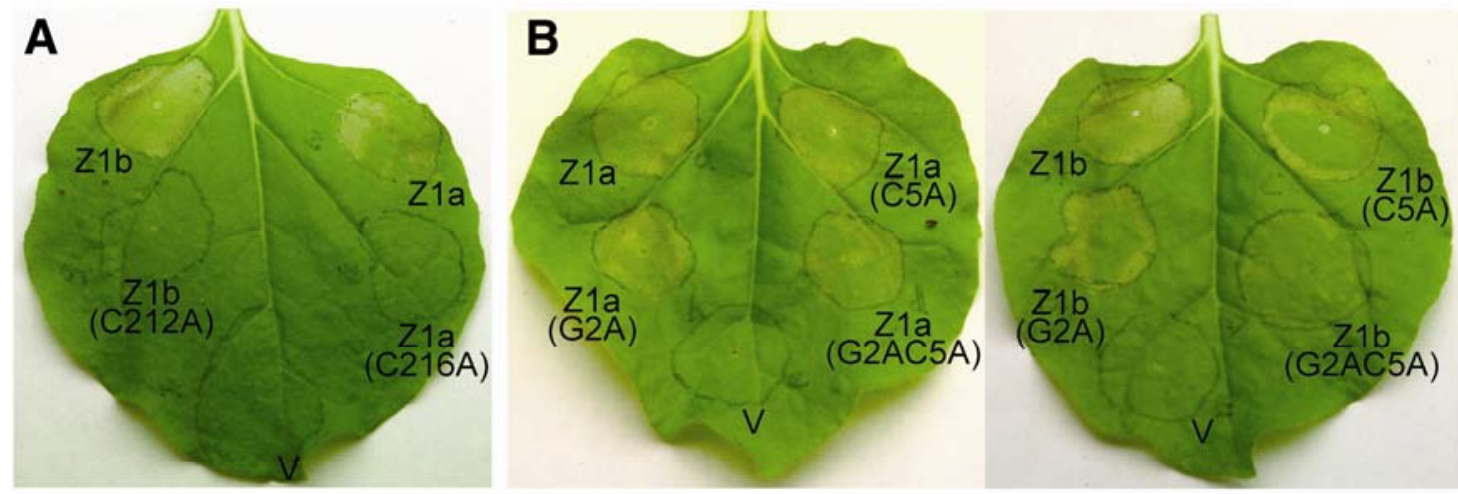

C

\begin{tabular}{|c|c|c|c|c|c|c|c|c|c|}
\hline MW & V & Z1a & $\begin{array}{c}\text { Z1a } \\
(\mathrm{G} 2 \mathrm{~A})\end{array}$ & $\begin{array}{c}\text { Z1a } \\
(\mathrm{C} 5 \mathrm{~A})\end{array}$ & $\begin{array}{c}\text { Z1a } \\
(\mathrm{G} 2 \mathrm{AC} 5 \mathrm{~A})\end{array}$ & Z1b & $\begin{array}{l}\text { Z1b } \\
\text { (G2A) }\end{array}$ & $\begin{array}{c}\text { Z1b } \\
\text { (C5A) }\end{array}$ & $\begin{array}{c}\text { Z1b } \\
\text { (G2AC5A) }\end{array}$ \\
\hline
\end{tabular}

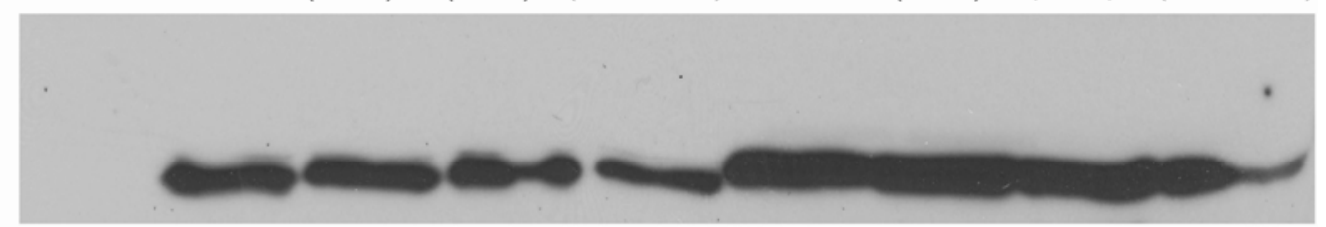

35

Fig. 3. HopZ1a and HopZ1b elicit hypersensitive response (HR)-like cell death in Nicotiana benthamiana using Agrobacterium spp.-mediated transient expression. Agrobacterium tumefaciens $\mathrm{C} 58 \mathrm{C} 1$ (pCH32) harboring pMDD1 containing the wild-type or mutant hopZ1 alleles, under the control of Cauliflower mosaic virus 35s promoter, were used to infiltrate 4-week-old $N$. benthamiana leaves. The HR-like cell death symptoms were monitored during a period of 36 to $72 \mathrm{~h}$ postinoculation (hpi). The experiments were repeated five times with similar results. The empty pMDD1 vector (V) was used as a negative control. A, HopZ1a and HopZ1b require the catalytic cysteine residue to trigger cell death in $N$. benthamiana. A. tumefaciens C58C1 (pCH32) harboring pMDD1::HopZ1a-HA, pMDD1::HopZ1a(C216A)-HA, pMDD1::HopZ1b-HA, and pMDD1::HopZ1b(C212A)-HA were pressure infiltrated in N. benthamiana leaves at an optical density at $600 \mathrm{~nm}\left(\mathrm{OD}_{600}\right)=0.1$. The leaf was photographed $72 \mathrm{hpi}$. B, The putative N-terminal myristoylation site (glycine2) and the putative palmitoylation site (cysteine5) are not required for HopZ1 a-triggered cell death but promote HopZ1b-triggered cell death in N. benthamiana. A. tumefaciens C58C1 (pCH32) harboring pMDD1::HopZ1a-HA, pMDD1::HopZ1a(G2A)-HA, pMDD1::HopZ1a(C5A)-HA, pMDD1::HopZ1a(G2AC5A)-HA, pMDD1::HopZ1b-HA, pMDD1:: HopZ1b(G2A)-HA, pMDD1::HopZ1b(C5A)-HA, and pMDD1::HopZ1b(G2AC5A)-HA were pressure infiltrated in N. benthamiana leaves at $\mathrm{OD}_{600}=0.4$. The leaves were photographed 60 hpi. HopZ1a(G2A), HopZ1a(C5A), and HopZ1a(G2AC5A) caused cell death symptoms that were indistinguishable from that of the wild-type HopZ1a, whereas HopZ1b(G2A), HopZ1b(C5A), and HopZ1b(G2AC5A) induced delayed and weaker cell death symptoms compared with the wildtype HopZ1b. C, Immunoblot of in planta expression of the wild-type and mutant HopZ1 proteins after Agrobacterium spp.-mediated transient expression in $N$. benthamiana. For each treatment, two leaf disks $\left(0.5 \mathrm{~cm}^{2}\right)$ infiltrated with Agrobacterium spp. were collected 24 hpi and total proteins were extracted. Hemagglutinin (HA)-tagged HopZ1 proteins were detected by anti-HA antibody conjugated with horseradish peroxidase. 


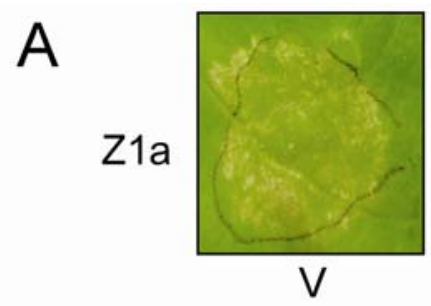

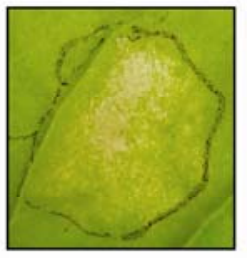

Z3

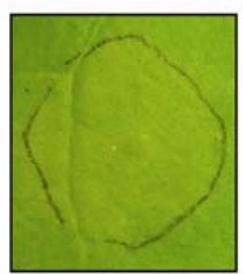

Z3

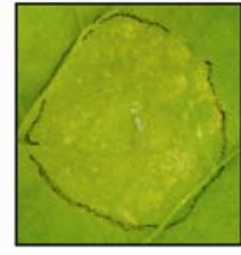

Z3(C300A)

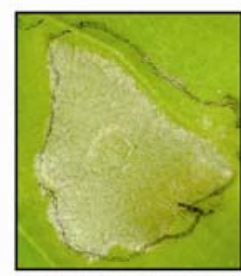

Z3(C300A)

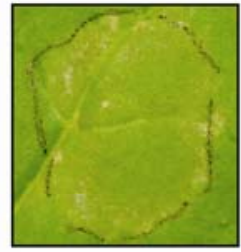

Z1c

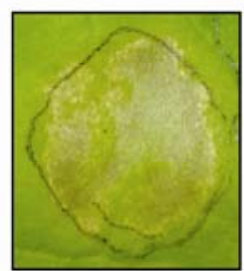

Z1c
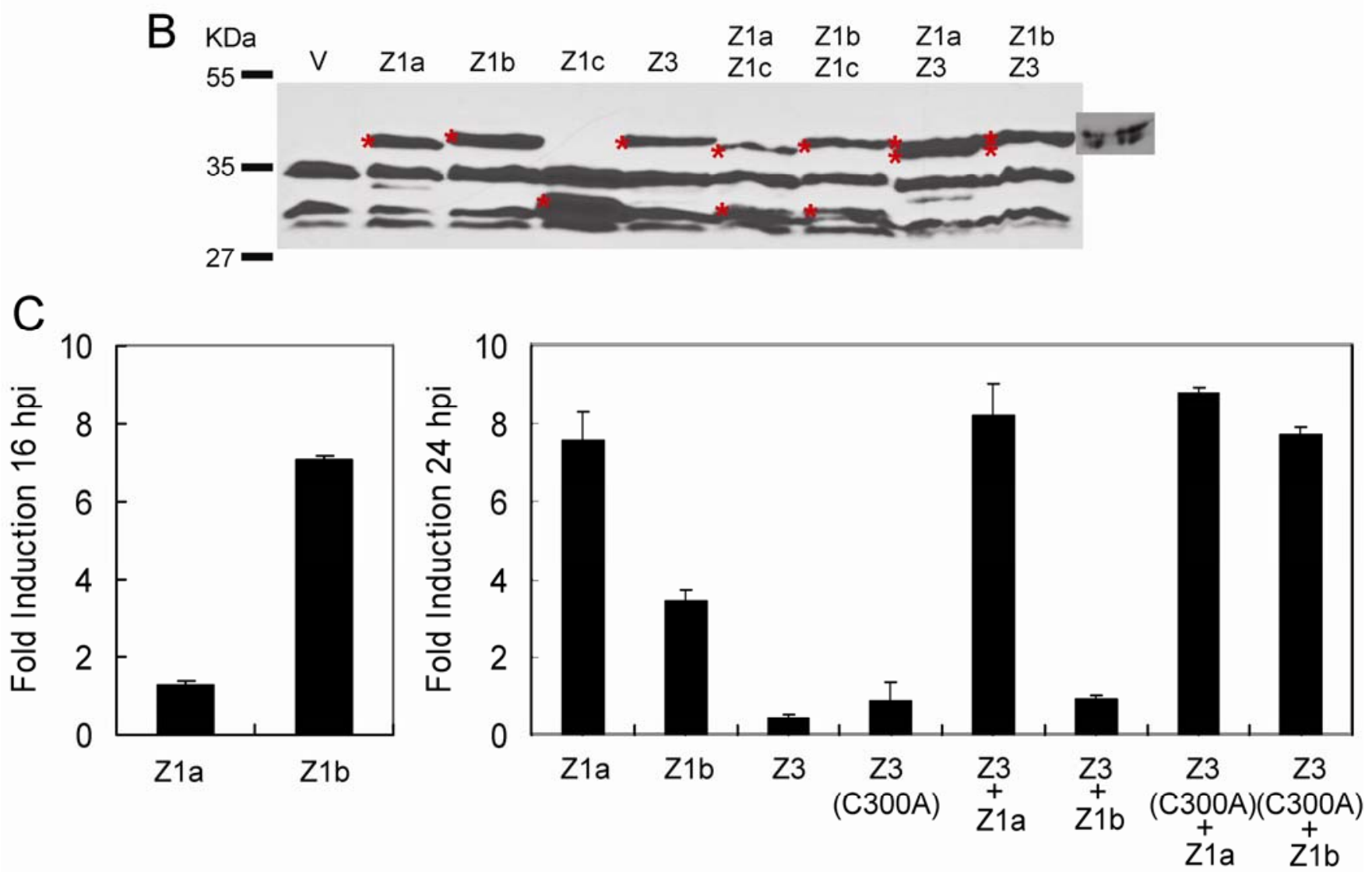

Fig. 4. HopZ3 suppresses the cell death triggered by HopZ1b but does not interfere with the cell death triggered by HopZ1a in Nicotiana benthamiana. A, Four-week-old $N$. benthamiana leaves were infiltrated with Agrobacterium tumefaciens $\mathrm{C} 58 \mathrm{C} 1$ ( $\mathrm{pCH} 32$ ) carrying one of the following plasmids: empty pMDD1 (V), pMDD1::HopZ3-HA, pMDD1::HopZ3(C300A)-HA, and pMDD1::HopZ1c-HA at an optical density at $600 \mathrm{~nm}\left(\mathrm{OD}_{600}\right)=0.4$. Four hours later, the same infiltrated leaf areas were infiltrated again with A. tumefaciens $\mathrm{C} 58 \mathrm{Cl}(\mathrm{pCH} 32)$ carrying pMDD1::HopZ1a-HA or pMDD1::HopZ1b-HA at OD $600=$ 0.1 . The leaves were photographed at $60 \mathrm{~h}$ postinoculation (hpi). The experiment was repeated five times with similar results. B, Immunoblot of in planta expression of the HopZ-HA proteins after Agrobacterium spp.-mediated transient expression in N. benthamiana leaf tissues. The asterisks indicate proteins of the predicted sizes of the effectors. Because HopZ1b and HopZ3 have similar molecular weights, another protein gel with better separation of the two proteins was presented in a separate panel. For each treatment, total proteins were extracted from two Agrobacterium spp.-infiltrated leaf disks $\left(0.5 \mathrm{~cm}^{2}\right)$ at 24 hpi. Hemagglutinin (HA)-tagged proteins were detected by anti-HA antibody conjugated with horseradish peroxidase. C, Real-time reverse-transcriptase polymerase chain reaction (RT-PCR) analysis of HopZ1b-induced PR-1a gene expression in $N$. benthamiana. Total RNA was extracted from $N$. benthamiana leaves transiently expressing HopZ1a, HopZ1b, HopZ3, and HopZ3(C300A) alone or co-expressing HopZ3 and HopZ1a, HopZ3 and HopZ1b, HopZ3(C300A) and HopZ1a, and HopZ3(C300A) and HopZ1b at 24 hpi. RNA samples were reverse transcribed and the cDNA produced was used as the template for real time RT-PCR using primers amplifying $P R-1 a$ and $N t$-Act 9 genes. The number of $P R$ - $1 a$ transcripts was normalized using the number of $N t$ $A c t 9$ transcripts from the same sample. $P R$ - $1 a$ induction, represented as fold difference, was determined by comparing the normalized $P R$ - $1 a$ transcripts from leaf tissues expressing HopZ1a and HopZ1b, or co-expressing HopZ1 and HopZ3, and HopZ1 and HopZ3(C300A), with that from the leaves infiltrated with A. tumefaciens carrying the empty pMDD1 vector (the mock treatment). PR-1a expression in N. benthamiana expressing HopZ1a or HopZ1b alone at 16 hpi was shown in a separate panel to demonstrate earlier $P R$ - $1 a$ induction by HopZ1b than HopZ1a. The experiments were repeated three times with similar results. Data from one representative experiment are presented. 
Quantitative RT-PCR analyses clearly demonstrated that $P R$ $1 a$ expression was induced by both HopZ1a and HopZ1b (Fig. 4C). HopZ1b-induced PR-1a expression (approximately sevenfold increase) was observed at $16 \mathrm{hpi}$; however, at that time, $P R-1 a$ was not induced in leaf tissues expressing HopZ1a (Fig. 4C). $P R-1 a$ induction was observed in HopZ1a-expressing leaf tissues at 24 hpi to a similar level as that observed in HopZ1bexpressing leaf tissues at $16 \mathrm{hpi}$ (Fig. 4C). HopZ1b alone induced $P R-1 a$ expression to a higher level at 16 than 24 hpi (approximately 3.6-fold), probably due to the cell death in the infiltrated leaf areas. Co-expression of HopZ3 and HopZ1a also induced $P R-1 a$ expression to a level similar to that of leaves expressing HopZ1a alone (Fig. 4C). Consistent with the phenotype that no cell death symptom was observed in $N$. benthamiana leaves co-expressing HopZ3 and HopZ1b, these leaf tissues also had no observable $P R-1 a$ induction. Moreover, $P R-1 a$ gene expression was induced in leaf tissues co-expressing HopZ3(C300A) and HopZ1b to a level (approximately sevenfold) similar to that of leaf tissues expressing HopZ1b alone (Fig. 4C). The delay in the $P R-1 a$ induction in leaf tissues co-expressing HopZ3(C300A) and HopZ1b compared with that expressing HopZ1b alone (24 versus 16 hpi) may be due to a reduced expression efficiency of HopZ1b because of the preinfiltration of $A$. tumefaciens carrying pMDD1:: HopZ3(C300A).

We next examined whether HopZ3 could suppress HopZ1btriggered HR by delivering the HopZ homologs into N. benthamiana through a natural T3SS. $P$. syringae pv. syringae B728a (PsyB728a) is virulent to $N$. benthamiana (Vinatzer et al. 2006). PsyB728a produces HopZ3 encoded in the exchangeable effector locus (EEL). pUCP20tk::HopZ1a-HA and pUCP20tk::HopZ1b-HA were introduced into PsyB728a, and these strains were infiltrated into $N$. benthamiana at $\mathrm{OD}_{600}=$ 0.00001. PsyB728a expressing HopZ1a showed an approximately 50-fold reduction in growth on $N$. benthamiana compared with $P s y$ B 728a or PsyB728a carrying the empty vector (Fig. 5B). On the contrary, PsyB728a expressing HopZ1b grew to a level similar to the parental strain PsyB728a, suggesting that the HopZ1b-triggered defense responses could be suppressed by other effectors secreted by PsyB728a. Consistent with the bacterial multiplication assays, the leaf areas infiltrated with PsyB728a expressing HopZ1b showed a watersoaking symptom representing disease development, similar to those infiltrated with $P s y \mathrm{~B} 728$ a carrying the empty vector (Fig. 5A). However, leaves infiltrated with PsyB728a expressing HopZ1a showed yellow spots, representing cell death triggered by HopZ1a.

In order to further confirm that the HopZ1b-triggered HR was suppressed by HopZ3 using a T3SS delivery system, we then conducted a second test using $P g y \mathrm{BR} 1$, which does not produce HopZ3 (Ma et al. 2006). For this purpose, we tested the ability of PgyBR1Rif and PgyBR1Rif-O1 to multiply in $N$. benthamiana. Three days after infiltration at $\mathrm{OD}_{600}=0.0001$, the population of PgyBR1Rif-O1 multiplied to a level comparable with that of PsyB728a on $N$. benthamiana (Fig. 5C). Furthermore, $P g y$ BR1-O1 caused a yellowing disease symptom in the infiltrated leaf areas (data not shown). However, the wildtype strain PsyBR1Rif showed an approximately 10-fold reduction in bacterial population compared with PgyBR1Rif-O1, probably due to the secretion of HopZ1b by PsyBR1Rif. Consistent with these results, expressing HopZ1a or HopZ1b in $P g y$ BR1Rif-O1 also resulted in an approximately 10 -fold reduction in bacterial population (Fig. 5B), indicating that these two HopZ1 alleles both triggered defense responses in $N$. ben-
A

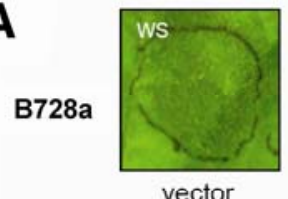

B

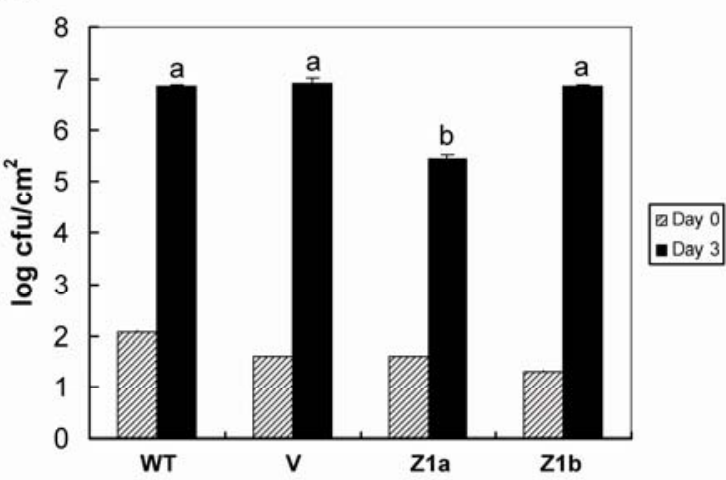

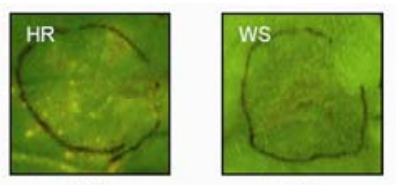

Z1b

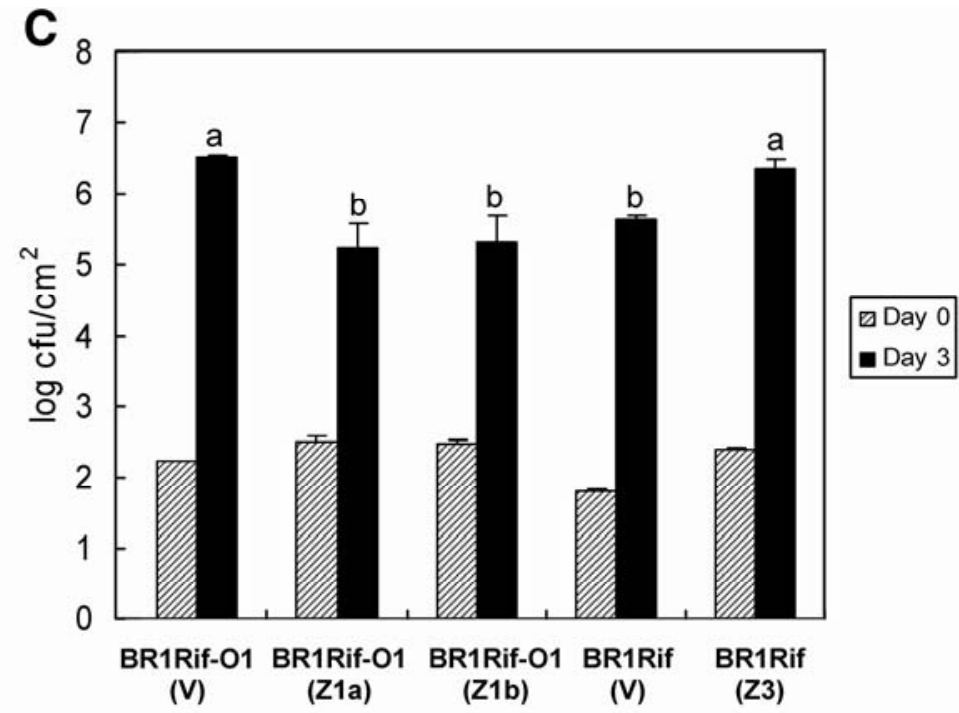

Fig. 5. HopZ3 suppresses HopZ1b-triggered defense response in Nicotiana benthamiana when the effectors are co-delivered through the type III secretion apparatus of Pseudomonas syringae. In the bacterial multiplication assays, each value represents the mean of bacterial populations in four leaves from four different plants at 0 and 3 days postinoculation. Error bars represent the standard errors. All experiments were repeated three times with similar results. Data from one representative experiment are presented. Values that are statistically different are labeled with different letters. A, N. benthamiana leaves were infiltrated with P. syringae pv. syringae strain B728a (PsyB728a) carrying one of the following plasmids: the empty vector pUCP20tk (V), pUCP20tk::HopZ1aHA (Z1a), or pUCP20tk::HopZ1b-HA (Z1b) using a concentration of $1 \times 10^{6} \mathrm{CFU} / \mathrm{ml}$ (optical density at $600 \mathrm{~nm}\left[\mathrm{OD}_{600}\right]=0.001$ ). Photographs of the infiltrated leaf areas were taken $72 \mathrm{~h}$ postinoculation. Water-soaking symptoms (ws) were observed in leaf areas infiltrated with $P s y \mathrm{~B} 728 \mathrm{a}$ carrying the empty vector or HopZ1b. Yellow hypersensitive response spots were observed in leaf areas infiltrated with PsyB728a-expressing HopZ1a. B, N. benthamiana leaves were infiltrated with PsyB728a (WT) or PsyB728a carrying one of the following plasmids: the empty vector pUCP20tk (V), pUCP20tk::HopZ1a-HA (Z1a), or pUCP20tk::HopZ1b-HA (Z1b) using a concentration of $1 \times 10^{4} \mathrm{CFU} / \mathrm{ml}\left(\mathrm{OD}_{600}=0.00001\right)$. C, $N$. benthamiana leaves were infiltrated with one of the following P. syringae pv. glycinea strains: BR1Rif carrying the empty pUCP20tk vector (BR1Rif(V)), BR1Rif carrying pUCP20tk::HopZ3-HA (BR1Rif(Z3)), BR1Rif-O1 carrying the empty pUCP20tk vector (BR1Rif-O1(V)), BR1Rif-O1 carrying pUCP20tk::HopZ1a-HA (BR1Rif-O1(Z1a)), or BR1Rif-O1 carrying pUCP20tk::HopZ1b-HA (BR1Rif-O1(Z1b)). The bacteria were infiltrated at a concentration of $\left.1 \times 10^{5} \mathrm{CFU} / \mathrm{ml}^{\left(\mathrm{OD}_{600}\right.}=0.0001\right)$. 
thamiana and that HopZ1b was responsible for the growth reduction of PgyBR1Rif. We then introduced HopZ3, with its native promoter and the cognate chaperone (SchZ3), into PgyBR1Rif. The introduction of HopZ3 restored the $P g y$ BR1Rif population to a level similar to that of PgyBR1RifO1 (Fig. 5C), probably due to the suppression of the HopZ1btriggered HR by HopZ3.

We also tested HopZ1c for its ability to suppress the HRlike cell death triggered by HopZ1a and HopZ1b. Infiltration of $N$. benthamiana leaves with HopZ1c prior to HopZ1a or HopZ1b did not suppress the cell death symptom elicited by the latter two effectors (Fig. 4A). This was not due to the instability of HopZ1c protein when co-expressing in N. benthamiana with HopZ1a or HopZ1b, as demonstrated by the Western blots (Fig. 4B). There is a possibility that HopZ1a and HopZ1b could interfere with each other in eliciting cell death in $N$. benthamiana but, because both HopZ1a and HopZ1b cause cell death, it is technically hard to test this possibility.

\section{DISCUSSION}

HopZ in $P$. syringae and their corresponding plant $R$ genes have been hypothesized to represent a co-evolutionary arms race (Ma et al. 2006). Diversification of the HopZ1 alleles is evidenced by the presence of three functional allelic variants and two degenerate alleles, with HopZ1a most resembling the ancestral allelic form (Ma et al. 2006). The avirulence function of HopZ1a in Arabidopsis was recently characterized (Lewis et al. 2008). It was shown that the HR triggered by HopZ1a was not dependent on any known $R$ genes in Arabidopsis; and that HopZ1a required a putative $\mathrm{N}$-myristoylation site for its membrane localization and avirulence function. Here, we further studied the stepwise co-evolutionary arms race between HopZ1 allelic variants and the corresponding plant defense systems by characterizing the virulence and avirulence functions of HopZ1 alleles in soybean using the natural soybean- $P$. syringae pv. glycinea pathosystem, as well as in $N$. benthamiana using Agrobacterium-mediated transient expression and $P$. syringae-mediated T3SS delivery.

HopZ1 alleles have distinct functions in soybean-HopZ1a triggers HR and restricts bacterial growth; HopZ1b, which is endogenously found in all the $P$. syringae pv. glycinea strains, promotes nonhost bacterial pathogen growth; and HopZ1c does not have an observable function under our experimental conditions. HopZ1b is located on the large endogenous pPgyBR1a plasmid and is flanked with multiple mobile-element-like sequences, including two identical transposaseencoding genes on both sides (data not shown). We suspect that plasmid copy number and the flanking mobile elements are responsible for the difficulties in making precise knock-out mutants of HopZ1b by homologous recombination. The plasmid-cured mutant PgyBR1Rif-O1 displayed a significant reduction on bacterial growth in soybean. However, the growth reduction of PgyBR1Rif-O1 could not be complemented by HopZ1b carried on pUCP20tk. PCR analysis indicated that pPgyBR1a also carried the gene cluster encoding coronatine (data not shown), which has been shown to play a key role in the early infection of $P$. syringae (Alarcon-Chaidez et al. 1999; Budde and Ullrich 2000; Melotto et al. 2006). It is most likely that the growth reduction of PgyBR1Rif-O1 is largely caused by the lack of coronatine production, and that HopZ1b does not seem to be a major contributor to the growth reduction. Many T3SEs have been found to have no observable effect on bacterial growth or disease symptoms on susceptible plant hosts, probably due to the subtle contribution of these effectors to virulence or to functional redundancy with other effectors (Alfano and Collmer 2004). Nonetheless, we observed a sig- nificant growth advantage conferred by HopZ1b to the growth of Pph1302A, a nonpathogen of soybean. The ability to promote nonhost bacterial growth has been demonstrated in T3SEs such as HopZ3 and HopAB1 in PsyB728a (Vinatzer et al. 2006) and HopZ2 in P. syringae pv. cilantro 0788-9 (Lewis et al. 2008) during infection of Arabidopsis. Taken together with the ubiquitous distribution of HopZ1b in P. syringae pv. glycinea strains, our experimental data strongly suggest that HopZ1b plays a role in facilitating bacterial infection of soybean. This is also consistent with our hypothesis that HopZ1b, as a derivative of a HopZ1a-like ancestral gene, not only evades host recognition but also maintains a virulence function.

T3SEs travel to different compartments in the plant cells after injection. The subcellular localization of these proteins is usually essential for their virulence or avirulence functions. For example, AvrBs3 from Xanthomonas campestris pv. vesicatoria contains a nuclear localization sequence (NLS) and its nuclear localization is required for the AvrBs3-mediated induction of defense responses in the resistant pepper plants (Szurek et al. 2002; Yang and Gabriel 1995). HopI1, a T3SEs from $P$. syringae pv. maculicola ES4326, localizes to the chloroplasts and suppresses plant defense (Guttman et al. 2002; Jelenska et al. 2007). Several effectors have been shown to localize to the plasma membrane after being acylated by eukaryote-specific mechanisms, especially myristoylation and palmitoylation. Disruption of myristoylation by mutating the key glycine residues in these effectors changes their localization in plant cells and leads to failure in triggering plant defense responses (de Vries et al. 2006; Lewis et al. 2008; Nimchuk et al. 2000; Shan et al. 2000; Thieme et al. 2007).

Several YopJ homologs in plant pathogens, such as HopZ1 and HopZ2 in P. syringae and XopJ in X. campestris pv. vesicatoria, have been reported to associate with the plant cell membrane, potentially through $\mathrm{N}$-myristoylation (Lewis et al. 2008; Thieme et al. 2007). Mutation of Gly2, the putative myristoylation site in HopZ1a, not only disrupted its membrane attachment but also abolished its avirulence activity in soybean, suggesting that the potential myristoylation site or myristoylation-mediated membrane localization was required for HopZ1a to trigger defense responses in soybean. In contrast, the potential myristoylation site of HopZ1b does not seem to be important for its virulence function, because our bacterial multiplication assay showed that HopZ1b(G2A) still conferred a growth advantage to Pph1302A in soybean to the same level as the wild-type HopZ1b.

Although HopZ1a and HopZ1b both trigger HR-like cell death when transiently expressed in $N$. benthamiana, the cell death symptoms appear to be different. HopZ1b elicits a faster and stronger cell death than HopZ1a does, as evidenced by the earlier appearance of $P R-1 a$ gene induction and HR-like cell death symptoms in the HopZ1b-expressing leaf spots. If our hypothesis that HopZ1 diversification has been driven by a coevolutionary arms race is valid, different plant defense responses should be induced by different HopZ1 alleles. Indeed, our experimental results demonstrated that the characteristics of the HR-like cell death elicited by HopZ1a and HopZ1b in N. benthamiana are different in two ways: i) the putative myristoylation and palmityolation sites had no observable effect on HopZ1a-triggered cell death, whereas they significantly promoted HopZ1b-triggered cell death; and ii) HopZ3 suppresses HopZ1b-induced cell death but does not seem to interfere with HopZ1a-induced cell death.

Although the potential myristoylation site is required for HopZ1a to trigger defense responses in soybean, it does not seem to contribute to the cell-death-eliciting activity of HopZ1a in $N$. benthamiana. We further confirmed that neither the putative myristoylation nor the putative palmitoylation site 
was required by HopZ1a to trigger defense responses by making two additional mutants, HopZ1a(C5A), with the putative palmitoylated Cys5 mutated, and HopZ1a(G2AC5A), with both the putatively myristoylated Gly 2 and palmitoylated Cys5 mutated. Transient expression of $\mathrm{HopZ} 1 \mathrm{a}(\mathrm{C} 5 \mathrm{~A})$ and HopZ1a(G2AC5A) still elicited cell death symptoms in $N$. benthamiana that were indistinguishable from those of HopZ1a, suggesting that HopZ1a might be differentially recognized in soybean and $N$. benthamiana. This is not unusual, because convergent evolution has been found in $R$ genes recognizing the T3SEs AvrB and AvrPto in different plants (Ashfield et al. 2004; Shan et al. 2000). On the contrary, HopZ1b(G2A) and HopZ1b(C5A) elicited a significantly delayed and weaker cell death symptom compared with that of the wild-type HopZ1b. Moreover, the double mutant HopZ1b(G2AC5A) triggered a cell death symptom even weaker than that triggered by the single mutants, indicating that both residues contributed to the HopZ1b-triggered cell death in $N$. benthamiana. It is likely that the potential N-terminal acylation of HopZ1b promotes host recognition of the T3SE, leading to HR by directing the membrane localization of HopZ1b in plant cells. These data suggest that, although both HopZ1a and HopZ1b elicit defense responses in N. benthamiana, different resistance pathways or recognition mechanisms seem to be used to detect these allelic variants.

Dual acylation often directs proteins to lipid rafts in membranes, which are hot spots for signaling factors (Linder and Deschenes 2007). A long list of T3SEs have been confirmed or predicted to contain potential fatty acylation motifs in their $\mathrm{N}$ termini (Maurer-Stroh and Eisenhaber 2004; Thieme et al. 2007). It is appealing to hypothesize that plant lipid rafts play a potentially important role in the defense network.

The difference between HopZ1a and HopZ1b was also evidenced by the observation that HopZ3 could suppress HopZ1btriggered HR but did not interfere with HopZ1a-triggered HR in $N$. benthamiana. Many T3SEs have been shown to have HRsuppressing activity (Abramovitch and Martin 2005; Bretz et al. 2003; Espinosa et al. 2003; Jamir et al. 2004). In fact, it has been proposed that HR-suppressing activity is one of the major functions of T3SEs in facilitating disease development (Grant et al. 2006). HopZ3 was previously demonstrated to suppress HR-like cell death triggered by several T3SEs of PsyB728a in N. benthamiana (Vinatzer et al. 2006). When we transiently expressed HopZ3 prior to HopZ1a or HopZ1b in the same leaf areas of $N$. benthamiana, HopZ3 was able to suppress the cell death symptom induced by HopZ1b but not that induced by HopZ1a. The ability of HopZ3 to inhibit HopZ1b-triggered HR-like cell death in $N$. benthamiana was confirmed by real-time RT-PCR analyses showing that no $P R-1 a$ gene induction was observed in leaf tissues co-expressing HopZ3 and HopZ1b, whereas HopZ1b alone induced a rapid increase (16 hpi) in the number of $P R-1 a$ transcripts.

Like HopZ1 alleles, HopZ3 also contains the conserved catalytic triad consisting of a histidine, a glutamic acid, and a cysteine. The cell-death-suppressing activity of HopZ3 depended on the predicted catalytic cysteine residue (Cys300), as evidenced by the loss of the inhibitory effect of HopZ3 (C300A) on HopZ1b-triggered cell death. We have previously shown that HopZ3 with Cys300 mutated lost its enzymatic activity (Ma et al. 2006). It is likely that the enzymatic activity of HopZ3 is required for its HR-suppressing activity.

We then further confirmed that the HopZ1b-triggered HR could be suppressed when delivered through the T3SS of $P$. syringae. We first expressed HopZ1a and HopZ1b in PsyB728a, which naturally secretes HopZ3 as a T3SE (Deng et al. 2003; Vinatzer et al. 2006). Bacterial multiplication assays demonstrated that the bacterial population of PsyB728a expressing
HopZ1a was approximately 50-fold lower than that of PsyB728a or PsyB728a expressing HopZ1b. These data suggest that the HopZ1b-triggered HR could be suppressed by other T3SEs secreted by PsyB728a, and that those PsyB728a T3SEs that suppress HopZ1b-triggered HR do not interfere with HopZ1a-triggered HR. We then used a P. syringae pv. glycinea strain to further confirm that the HopZ1b-triggered defense responses in $N$. benthamiana were suppressed by HopZ3. HopZ1b is an endogenous T3SE produced by the soybean pathogen PgyBR1. Due to the defense responses triggered by HopZ1b in $N$. benthamiana, the bacterial population of PgyBR1Rif was approximately 10-fold lower than that of PgyBR1Rif-O1. This was supported by the 10 -fold reduction of bacterial multiplication in $N$. benthamiana of PgyBR1RifO1 expressing HopZ1b. When HopZ3 was introduced into $P g y \mathrm{BR} 1$, the bacterial population was restored to a level similar to that of PgyBR1Rif-O1. This growth increase is not likely due to a direct growth promotion effect of HopZ3 on bacterial multiplication in $N$. benthamiana because HopZ3 seems to have a quantitative avirulence function on $P$ syB 728a multiplication in $N$. benthamiana (Vinatzer et al. 2006). Therefore, the increased bacterial population of PgyBR1Rif expressing HopZ3 in $N$. benthamiana was more likely due to an inhibitory effect of HopZ3 on HopZ1b-triggered HR. In all the bacterial multiplication experiments, the expression of HopZ1a always led to a reduction in $P$. syringae population no matter whether the bacterium produced HopZ3 or not. These data, consistent with the transient expression assays, confirmed that, although HopZ1a and HopZ1b both induced HR in N. benthamiana, they appeared to trigger different signaling pathways.

The HopZ1c allele did not suppress the HR triggered by HopZ1a or HopZ1b, indicating that there is no negative dominant activity of HopZ1c on the other two closely related allelic variants. It is noteworthy that HopZ1b and HopZ1c share 97\% identity in their amino acid sequences, and the major difference is at the C-termini of the proteins, where HopZ1c has a frame-shift mutation leading to a shorter protein product (HopZ1c is 260 amino acids in length, whereas HopZ1b is 364 amino acids in length). Considering the evidence that HopZ3 requires its intact catalytic triad and, most likely, its enzymatic activity for its HR-suppressing activity, it suggests that the cell-death-interfering activity of HopZ3 is probably not due to the competitive binding of HopZ3 to the same plant substrates of HopZ1b. Rather, the evidence implies that HopZ3 targets the signaling pathway downstream of HopZ1b recognition. Again, these data support our hypothesis that HopZ1a and HopZ1b are differently recognized in $N$. benthamiana.

A co-evolutionary arms race leads to escalatory adaptations in both pathogens and their hosts. Using the natural P. syringae pv. glycinea-soybean pathosystem, we demonstrated that the three allelic variants of HopZ1 have distinct functions. By characterizing the cell-death-eliciting activity of HopZ1 alleles in $N$. benthamiana, our data suggested that HopZ1 diversification was matched by the differentiation of the corresponding plant resistance systems.

\section{MATERIALS AND METHODS}

\section{Bacterial strains and plasmids.}

P. syringae strains were grown at $30^{\circ} \mathrm{C}$ in King's B medium (King et al. 1954) or M63 minimal medium containing $1 \%$ fructose for the induction of T3SS (Bretz and Hutcheson 2004). Plasmids were introduced into $P$. syringae by electroporation using an Eppendorf electroporator 2510 (Eppendorf North America Inc., Westbury, NY, U.S.A.) according to the manufacturer's instructions. A. tumefaciens and Escherichia coli were grown in Luria-Bertani medium (BD Co., Franklin Lakes, 
NJ, U.S.A.) at 30 or $37^{\circ} \mathrm{C}$, respectively. Transformation of plasmids to A. tumefaciens and E. coli were accomplished by introducing plasmid DNA to chemical competent cells as previously described (Sambrook and Russell 2001). Appropriate antibiotics were supplemented to the media when necessary.
Antibiotics were used at the following concentrations: ampicillin, $100 \mu \mathrm{g} / \mathrm{ml}$; kanamycin, $50 \mu \mathrm{g} / \mathrm{ml}$; rifampicin, $50 \mu \mathrm{g} / \mathrm{ml}$; and tetracycline, $10 \mu \mathrm{g} / \mathrm{ml}$.

Bacteria strains and plasmids used in this study are summarized in Table 1.

Table 1. Bacteria strains and plasmids

\begin{tabular}{|c|c|c|}
\hline Strains or plasmids & Description $^{a}$ & Source or reference \\
\hline Escherichia coli $\mathrm{DH} 5 \alpha$ & $\begin{array}{l}\text { F-Ф80dlacZ } \Delta \mathrm{M} 15 \Delta \text { (lacZYA-argF) U169 recA1 endA1, hsdR17(rk-, } \\
\text { mk+) phoA supE44 } \lambda \text { - thi-1 gyrA96 relA1 }\end{array}$ & Invitrogen, Carlsbad, CA, U.S.A. \\
\hline Pseudomonas syringae pv. glycinea $\mathrm{BR} 1$ & Isolated from soybean & MAFF no. 210373 \\
\hline P. syringae pv. glycinea BR1Rif & Rifampicin spontaneous mutant of $P g y \mathrm{BR} 1, \mathrm{Rif}^{\mathrm{r}}$ & This study \\
\hline P. syringae pv. glycinea BR1Rif-O1 & Endogenous plasmid (containing hopZ1b) cured line of PgyBR1Rif, Rif ${ }^{\mathrm{r}}$ & This study \\
\hline P. syringae pv. glycinea BR1Rif::hrcJ RnptII & T3SS knock-out mutant of PgyBR1Rif, Rif ${ }^{\mathrm{r}}, \mathrm{Kan}^{\mathrm{r}}$ & This study \\
\hline P. syringae pv. phaseolicola $1302 \mathrm{~A}$ & Isolated from kidney bean & D. L. Arnold \\
\hline P. syringae pv. phaseolicola $1302 \mathrm{ARif}$ & Rifampicin spontaneous mutant of $P p h 1302 \mathrm{~A}, \mathrm{Rif}^{\mathrm{r}}$ & This study \\
\hline P. syringae pv. syringae $\mathrm{B} 728 \mathrm{a}$ & Isolated from snap bean, Rif $^{\mathrm{r}}$ & Hickman et al. 1987 \\
\hline Agrobacterium tumefaciens $\mathrm{C} 58 \mathrm{C} 1$ (pCH32) & $\operatorname{Rif}^{\mathrm{r}}, \mathrm{Tet}^{\mathrm{r}}$ & M. B. Mudgett \\
\hline pUCP20tk & Plasmid vector of $P$. syringae, derived from pUCP20, $\mathrm{Kan}^{\mathrm{r}}$ & West et al. 1994; P. W. Wang \\
\hline pUCP20tk::HopZ1-HA & $\begin{array}{l}\text { HopZ1 alleles tagged with HA and under the control of their native } \\
\text { promoters were inserted in pUCP20tk, } \operatorname{Kan}^{\mathrm{r}}\end{array}$ & Lewis et al. 2008; Ma et al. 2006 \\
\hline pUCP20tk::HopZ1a(C216)-HA & $\begin{array}{l}\text { HopZ1a including its native promoter and with cysteine } 216 \text { replaced with } \\
\text { an alanine was inserted in pUCP20tk, } \mathrm{Kan}^{\mathrm{r}}\end{array}$ & Lewis et al. 2008 \\
\hline pUCP20tk::HopZ1a(G2A)-HA & $\begin{array}{l}\text { HopZ1a including its native promoter and with glycine } 2 \text { replaced with an } \\
\text { alanine was inserted in pUCP20tk, } \mathrm{Kan}^{\mathrm{r}}\end{array}$ & This study \\
\hline pUCP20tk::HopZ1b(C212A)-HA & $\begin{array}{l}\text { HopZ1b including its native promoter and with cysteine } 212 \text { replaced with } \\
\text { an alanine was inserted in pUCP20tk, } \operatorname{Kan}^{\mathrm{r}}\end{array}$ & Lewis et al. 2008 \\
\hline pUCP20tk::HopZ1b(G2A)-HA & $\begin{array}{l}\text { HopZ1b including its native promoter and with glycine } 2 \text { replaced with an } \\
\text { alanine was inserted in pUCP20tk, } \operatorname{Kan}^{r}\end{array}$ & This study \\
\hline pUCP20tk::HopZ3-HA & $\begin{array}{l}\text { pUCP20tk carrying HopZ3 tagged with HA, under the control of its native } \\
\text { promoter and the chaperone } S \operatorname{chZ}, \operatorname{Kan}^{\mathrm{r}}\end{array}$ & This study \\
\hline pMDD1::HopZ1a-HA & $\begin{array}{l}\text { HopZ1a tagged with HA and inserted in pMDD1 under the control of } \\
\text { CaMV 35s promoter, } \operatorname{Kan}^{r}\end{array}$ & Ma et al. 2006 \\
\hline pMDD1::HopZ1a(C216A)-HA & $\begin{array}{l}\text { HopZ1a with cysteine } 216 \text { replaced with an alanine in pMDD1 under the } \\
\text { control of CaMV } 35 \text { s promoter, } \operatorname{Kan}^{\mathrm{r}}\end{array}$ & Ma et al. 2006 \\
\hline pMDD1::HopZ1a(G2A)-HA & $\begin{array}{l}\text { HopZ1a with glycine } 2 \text { replaced with an alanine in pMDD1 under the } \\
\text { control of CaMV } 35 \text { s promoter, } \mathrm{Kan}^{\mathrm{r}}\end{array}$ & This study \\
\hline pMDD1::HopZ1a(C5A)-HA & $\begin{array}{l}\text { HopZ1a with cysteine } 5 \text { replaced with an alanine in pMDD1 under the } \\
\text { control of CaMV } 35 \text { s promoter, } \operatorname{Kan}^{\mathrm{r}}\end{array}$ & This study \\
\hline pMDD1::HopZ1a(G2AC5A)-HA & $\begin{array}{l}\text { HopZ1a with glycine } 2 \text { and cysteine } 5 \text { replaced with alanines in pMDD1 } \\
\text { under the control of CaMV } 35 \text { s promoter, } \operatorname{Kan}^{\mathrm{r}}\end{array}$ & This study \\
\hline pMDD1::HopZ1b-HA & $\begin{array}{l}\text { HopZ1b tagged with HA and inserted into pMDD1 under the control of } \\
\text { CaMV 35s promoter, } \operatorname{Kan}^{\mathrm{r}}\end{array}$ & Ma et al. 2006 \\
\hline pMDD1::HopZ1b(C212A)-HA & $\begin{array}{l}\text { HopZ1b with cysteine } 212 \text { replaced with an alanine in pMDD1 under the } \\
\text { control of CaMV } 35 \text { s promoter, } \operatorname{Kan}^{r}\end{array}$ & This study \\
\hline pMDD1::HopZ1b(G2A)-HA & $\begin{array}{l}\text { HopZ1b with glycine } 2 \text { replaced with an alanine in pMDD1 under the } \\
\text { control of CaMV } 35 \text { s promoter, } \operatorname{Kan}^{\mathrm{r}}\end{array}$ & This study \\
\hline pMDD1::HopZ1b(C5A)-HA & $\begin{array}{l}\text { HopZ1b with cysteine } 5 \text { replaced with an alanine in pMDD1 under the } \\
\text { control of CaMV } 35 \text { s promoter, } \operatorname{Kan}^{\mathrm{r}}\end{array}$ & This study \\
\hline pMDD1::HopZ1b(G2AC5A)-HA & $\begin{array}{l}\text { HopZ1b with glycine } 2 \text { and cysteine } 5 \text { replaced with alanines in pMDD1 } \\
\text { under the control of CaMV } 35 \text { s promoter, } \operatorname{Kan}^{\mathrm{r}}\end{array}$ & This study \\
\hline pMDD1::HopZ1c-HA & $\begin{array}{l}\text { HopZ1c tagged with HA and inserted into pMDD1 under the control of } \\
\text { CaMV 35s promoter, } \operatorname{Kan}^{\mathrm{r}}\end{array}$ & Ma et al. 2006 \\
\hline pMDD1::HopZ3-HA & $\begin{array}{l}\text { HopZ3 without its cognitive chaperone SchZ3 was tagged with HA and } \\
\text { inserted into pMDD1 under the control of CaMV } 35 \text { s promoter, Kan }{ }^{r}\end{array}$ & Ma et al. 2006 \\
\hline pMDD1::HopZ3(C300A)-HA & $\begin{array}{l}\text { HopZ3 with cysteine } 300 \text { replaced with an alanine in pMDD1 under the } \\
\text { control of CaMV } 35 \text { s promoter, } \operatorname{Kan}^{\mathrm{r}}\end{array}$ & This study \\
\hline pAVA319 & pBluescript based vector containing CaMV 35s promoter and $g f p, \mathrm{Amp}^{\mathrm{r}}$ & von Arnim et al. 1998 \\
\hline pAVA319::YFP & $y f p$, replacing $g f p$, was inserted into pAVA319, Amp ${ }^{\mathrm{r}}$ & Z. Yang \\
\hline pAVA319::HopZ1a-YFP & $\begin{array}{l}\text { HopZ1a tagged with YFP at the C-terminus was inserted in pAVA319, } \\
\text { Amp }^{r}\end{array}$ & This study \\
\hline pAVA319::HopZ1a(G2A)-YFP & $\begin{array}{l}\text { HopZ1a mutant with glycine } 2 \text { replaced with an alanine was inserted into } \\
\text { pAVA319::YFP, Amp }{ }^{\mathrm{r}}\end{array}$ & This study \\
\hline pAVA319::HopZ1b-YFP & $\begin{array}{l}\text { HopZ1b tagged with YFP at the C-terminus was inserted in pAVA319, } \\
\text { Amp }^{r}\end{array}$ & This study \\
\hline pAVA319::HopZ1b(C212A)-YFP & $\begin{array}{l}\text { HopZ1b mutant with cystine } 212 \text { replaced with an alanine was tagged with } \\
\text { YFP at the C-terminal and inserted in pAVA319, } \mathrm{Amp}^{\mathrm{r}}\end{array}$ & This study \\
\hline pAVA319::HopZ1b(G2A)-YFP & $\begin{array}{l}\text { HopZ1b mutant with glycine } 2 \text { replaced with an alanine was tagged with } \\
\text { YFP and inserted into pAVA319, } \mathrm{Amp}^{\mathrm{r}}\end{array}$ & This study \\
\hline pAVA319::HopZ1c-YFP & HopZ1c tagged with YFP at the C-terminus in pAVA319, $\mathrm{Amp}^{\mathrm{r}}$ & This study \\
\hline pAVA319::HopZ1c(G2A)-YFP & $\begin{array}{l}\text { HopZ1c mutant with glycine } 2 \text { replaced with an alanine was tagged with } \\
\text { YFP and inserted into pAVA319, Amp }\end{array}$ & This study \\
\hline
\end{tabular}

${ }^{\mathrm{a}} \mathrm{Rif}^{\mathrm{r}}, \mathrm{Kan}^{\mathrm{r}}, \mathrm{Tet}^{\mathrm{r}}$, and $\mathrm{Amp}^{\mathrm{r}}=$ resistant to rifampicin, kanamycin, tetracycline, and ampicillin, respectively; T3SS $=$ type III secretion system; CaMV = Cauliflower mosaic virus; YFP and GFP = yellow and green fluorescent protein, respectively. 
Gene cloning and plasmid construction.

HopZ proteins were cloned into a broad-host-range vector pUCP20tk, which was derived from pUCP20 (West et al. 1994), with the ampicillin resistance gene replaced by a kanamycin resistance gene (P. W. Wang, personal communication). hopZ genes were cloned under their native promoters, including the hrp boxes. They also contain an in-frame hemagglutinin (HA) tag at the C-termini. Site-directed mutagenesis was accomplished by introducing the mutations into PCR primers used to amplify the genes. pUCP20tk carrying the wild-type and mutated hopZ genes were transformed into $P$. syringae by electroporation.

For Agrobacterium-mediated transient expression, hopZl wild-type and mutant genes were cloned into a binary vector pMDD1 under the control of Cauliflower mosaic virus (CaMV) 35s promoter (Mudgett et al. 2000). hopZ3 and hopZ3(C300A) were cloned into pMDD1 without its cognate chaperone (SchZ3) sequence. All proteins were tagged with $\mathrm{HA}$ at the $\mathrm{C}$-termini. The resulting plasmids were then transformed into A. tumefaciens $\mathrm{C} 58 \mathrm{C} 1$ (pCH32) by chemical transformation (Van Larebeke et al. 1974).

To determine the subcellular localizations of HopZ1, the coding region of hopZ1 genes were in-frame fused to the $y f p$ gene at the C-termini in the vector pAVA319 (von Arnim et al. 1998). The expression of the fusion proteins were under the control of CaMV 35s promoter. The resulting plasmids were then transiently expressed in onion epidermal cells via particle bombardment as previously described (von Arnim and Deng 1994).

Oligonucleotide sequences used as primers in PCR reactions to generate the recombinant plasmids are listed in Table 2.

\section{Plasmid curing in $P$. syringae pv. glycinea BR1Rif.}

Curing of the plasmid in $P$. syringae pv. glycinea BR1Rif was carried out according to the previously described method using acridine orange (Trevors 1986). An overnight culture of $P g y$ BR1Rif was inoculated at an initial concentration of $10^{4}$ to $10^{5}$ cells $/ \mathrm{ml}$ in King's B medium containing acridine orange (10 to $100 \mu \mathrm{g} / \mathrm{ml}$ ), and then grown at $30^{\circ} \mathrm{C}$ with agitation until bacterial growth became visible. Aliquots from the highest concentration of acridine orange that still allowed bacterial growth were serially diluted and spread onto King's B agar plates. Individual colonies were examined for the absence of hopZlb by PCR.
Construction of the $P$. syringae pv. glycinea BR1Rif T3SS knock-out mutant.

A T3SS loss-of-function mutant was constructed by disrupting the $h r c J$ gene in $P g y$ BR1Rif with a kanamycin resistance gene (nptII). PCR product containing the hrcJ gene disrupted with nptII was cloned into pEX18Tc (Hoang et al. 1998), a suicidal plasmid in $P$. syringae. The resulting plasmid pEX18Tc::hrcJ nntII was introduced into PgyBR1Rif by electroporation, and double-crossover mutants with the endogenous $h r c J$ replaced by the disrupted gene were identified as kanamycin resistant and tetracycline sensitive, and then further confirmed by PCR.

\section{Bacteria growth assays and HR assays on soybean and $N$. benthamiana.}

Soybean (Glycine $\max$ (L.) cv. OAC Bayfield) seed were surface sterilized with $10 \%$ bleach for 10 min and pregerminated on wet filter paper at room temperature in the dark for 4 days. The seedlings were then transplanted to soil and grown in a greenhouse at an ambient temperature of 25 to $30^{\circ} \mathrm{C}$ under natural light conditions.

For bacterial multiplication assays in soybean, 9-day-old soybean plants with fully developed unifoliates were sprayed with $P$. syringae cell suspensions at an $\mathrm{OD}_{600}=0.2$ (approximately $2 \times 10^{8} \mathrm{CFU} / \mathrm{ml}$ ) in $10 \mathrm{mM} \mathrm{MgSO}_{4}$ using a commercial air brush and an air compressor (approximately 40 psi). Following inoculation, the plants were transferred to a growth chamber with $22^{\circ} \mathrm{C}, 90 \%$ humidity, and a 16-h photoperiod. To determine the in planta growth of the bacteria, four leaf discs $\left(0.5 \mathrm{~cm}^{2}\right)$ were taken from each inoculated leaf, briefly surface sterilized in $70 \%$ ethanol, and then homogenized in $10 \mathrm{mM}$ $\mathrm{MgSO}_{4}$. Serial dilutions were subsequently plated onto King's $\mathrm{B}$ agar plates with appropriate antibiotics to determine the CFU.

For HR assays in soybean, PgyBR1Rif-O1 carrying HopZ1 in pUCP20tk was grown on King's B agar overnight. The cells were scraped from the agar and suspended in $5 \mathrm{mM}$ morpholineethanesulfonic acid (pH 5.6) at $\mathrm{OD}_{600}$ of 0.5 , then hand infiltrated into the unifoliates of 14-day-old soybean using a needleless syringe. The infiltrated plants were kept in a growth chamber with high humidity (approximately 90\%) for $48 \mathrm{~h}$. Infiltrated leaves were then harvested and bleached in $90 \%$ ethanol for a better visualization of the cell death symptoms.

Table 2. Oligonucleotides used in this research

\begin{tabular}{|c|c|c|}
\hline Name $^{a}$ & Sequence & Restriction sites \\
\hline \multicolumn{3}{|l|}{ Construction of HopZ1 mutants } \\
\hline HopZ1a(G2A) forward & AGTGGATCCATGGCAAATGTATGCGTCGG & BamHI \\
\hline HopZ1a(C5A) forward & AGAGGATCCATGGGAAATGTAGCCGTCGG & BamHI \\
\hline HopZ1a(G2AC5A) forward & AGAGGATCCATGGCAAATGTAGCCGTCGG & BamHI \\
\hline HopZ1b $(G 2 A)$ forward & AGTGGATCCATGGCAAATATATGCATCGGC & BamHI \\
\hline HopZ1b(C5A) forward & AGAGGATCCATGGGAAATATAGCCATCGGC & BamHI \\
\hline HopZ1b(G2AC5A) forward & AGAGGATCCATGGCAAATATAGCCATCGGC & BamHI \\
\hline HA tag reverse & AGTCTCGAGTTAGCTGGCGTAGTCCGG & XhoI \\
\hline \multicolumn{3}{|l|}{ Construction of YFP fusion proteins } \\
\hline HopZ1a-YFP forward & TCACCATGGGAAATGTATGCGTCGG & NcoI \\
\hline HopZ1a(G2A)-YFP forward & TCACCATGGCAAATGTATGCGTCGG & NcoI \\
\hline HopZ1a-YFP reverse & CAACCATGGAGCGCTGCTCTTCGGCAAG & NcoI \\
\hline HopZ1b/c-YFP forward & GCACCATGGGAAATATATGCATCGG & NcoI \\
\hline HopZ1b/c(G2A)-YFP forward & GCACCATGGCAAATATATGCATCGG & NcoI \\
\hline HopZ1b-YFP reverse & CATCCATGGAGCCCTGAGCCGCAGCCAA & NcoI \\
\hline HopZ1c-YFP reverse & AGTCCATGGAAAAGTGCCCGCAGTGGTC & NcoI \\
\hline \multicolumn{3}{|c|}{ Construction of T3SS knock-out mutant } \\
\hline hrcJ-35 & CATGCCAAACAGCAGCAGCCCT & $\ldots$ \\
\hline hrcJ+797 & GCGTGCTTGATGGAGCTGATTGC & $\ldots$ \\
\hline hrpS+515 & CGGGATCTGTACTTTCGCCTTAACG & $\ldots$ \\
\hline hrcC-19 & CCCGATCAACAATAAAGGCAACCA & $\ldots$ \\
\hline
\end{tabular}

${ }^{\mathrm{a}} \mathrm{HA}=$ hemagglutinin, $\mathrm{YFP}$ = yellow fluorescent protein, and T3SS = type III secretion system. 
For bacterial multiplication assays in $N$. benthamiana, $P$. syringae strains were grown overnight on King's $\mathrm{B}$ agar. The cells scraped from the agar were suspended in $10 \mathrm{mM} \mathrm{MgSO}_{4}$ at $\mathrm{OD}_{600}$ of 0.00001 (for $P$. syringae pv. syringae) or $\mathrm{OD}_{600}$ of 0.0001 (for $P$. syringae pv. glycinea) and used to infiltrate fully expanded leaves on 4-week-old $N$. benthamiana plants. The inoculated plants were kept at room temperature with a 16-h photoperiod. Four leaf discs $\left(0.5 \mathrm{~cm}^{2}\right)$ were taken from each inoculated leaf, briefly surface sterilized in $70 \%$ ethanol, and then homogenized in $10 \mathrm{mM} \mathrm{MgSO}_{4}$. Serial dilutions were subsequently plated onto King's B agar plates with appropriate antibiotics to determine the CFU.

For HR assays in $N$. benthamiana, $P$. syringae cell suspensions in $10 \mathrm{mM} \mathrm{MgSO}_{4}$ at $\mathrm{OD}_{600}$ of 0.0001 were used to infiltrate fully expanded $N$. benthamiana leaves. Photos of the infiltrated leaves were taken $72 \mathrm{hpi}$.

\section{Agrobacterium-mediated transient expression assays.}

A. tumefaciens $\mathrm{C} 58 \mathrm{C} 1$ ( $\mathrm{pCH} 32$ ) harboring the binary vector pMDD1 carrying hopZl genes was used for transiently expressing the bacterial proteins in 4-week-old $N$. benthamiana plants using a needleless syringe as previously described (Ma et al. 2006; Szurek et al. 2001). Inoculated plants were kept at room temperature under continuous low light and cell death symptoms were monitored for 36 to 72 hpi. The empty pMDD1vector was used as a negative control.

For HR suppression assays, $N$. benthamiana leaves were first infiltrated with A. tumefaciens $\mathrm{C} 58 \mathrm{C} 1$ (pCH32) carrying pMDD1::HopZ3-HA, pMDD1::HopZ3(C300A)-HA, or pMDD1::HopZ1c-HA at $\mathrm{OD}_{600}=0.4$. Four hours later, the same infiltrated areas were infiltrated again with $A$. tumefaciens $\mathrm{C} 58 \mathrm{C} 1$ (pCH32) harboring pMDD1::HopZ1a-HA or pMDD1::HopZ1b-HA at $\mathrm{OD}_{600}=0.1$. The plants were kept at room temperature under continuous low light for 48 to $72 \mathrm{~h}$. The empty pMDD1 vector was used as a negative control.

\section{Real-time RT-PCR analysis.}

The expression of $P R-1 a$ gene in $N$. benthamiana leaf tissues was analyzed by real-time RT-PCR using the fluorescent intercalating dye SYBR-Green (SensiMix Plus SYBR \& Fluorescein; Quantace Inc., Norwood, MA, U.S.A.) and an iQ5 Real-Time PCR Detection System (BioRad Laboratories, Hercules, CA, U.S.A.). Total RNA was isolated from three independent biological replicates using a hot phenol extraction method (Salter and Conlon 2007). DNA contamination was removed from samples using DNase I (Fermentas Inc., Hanover, MD, U.S.A.). Reverse transcription was performed using MMLV Reverse Transcriptase (Promega Corp., Madison, WI, U.S.A.) with $10 \mu \mathrm{g}$ of total RNA in a total reaction of $25 \mu \mathrm{l}$. The cDNAs were then used as templates for real-time PCR using gene-specific primers for $P R-I a$ and $N t-A c t 9$ (as an internal quantitative control). Real-time PCR conditions and primer sequences used for amplifying $P R-1 a$ and $N t$-Act 9 were as previously described (Riviere et al. 2008). The number of $P R-1 a$ transcripts was normalized using the number of Nt-Act 9 transcripts from the same sample. $P R-1 a$ induction was determined by comparing the normalized $P R-1 a$ transcripts from leaf tissues expressing HopZ1a, HopZ1b or co-expressing HopZ1 and HopZ3, HopZ1, and HopZ3(C300A) with that from the leaves infiltrated with $A$. tumefaciens carrying the empty pMDD1 vector (the mock treatment).

\section{Protein analysis.}

$P$. syringae expressing hopZ1 carried on pUCP20tk was grown in King's B medium with appropriate antibiotics at $30^{\circ} \mathrm{C}$ overnight. The bacteria cells were washed once, resuspended in M63 minimal medium supplemented with $1 \%$ fruc- tose at $\mathrm{OD}_{600}$ of 0.2 , and incubated with agitation at room temperature overnight. The induced bacterial cell cultures were normalized to $\mathrm{OD}_{600}=0.2$, and cells from $1 \mathrm{ml}$ of the induced culture were collected. The induced cells were resuspended in $2 \times$ Laemmli buffer and then boiled for 5 min (Laemmli 1970). Total bacteria proteins were separated by sodium dodecyl sulfate polyacrylamide gel electrophoresis (SDS-PAGE) and HopZ1 expression was detected by Western blots using antiHA antibody conjugated with horseradish peroxidase (HRP) (Santa Cruz Biotechnology Inc., Santa Cruz, CA, U.S.A.)

To confirm HopZ protein expression in $N$. benthamiana after Agrobacterium infiltration, two leaf disks $\left(0.5 \mathrm{~cm}^{2}\right)$ were collected from the infiltrated areas and homogenized in $100 \mu \mathrm{l}$ of $2 \times$ Laemmli buffer on ice. Protein samples were boiled for 5 min and then the plant tissue debris were spun down by centrifuging the samples $(12,000 \mathrm{rpm})$ at $4^{\circ} \mathrm{C}$ for $10 \mathrm{~min}$. In all, $20 \mu \mathrm{l}$ of supernatant from each sample was separated on SDSPAGE gels and HopZ protein expression was detected by Western blots using anti-HA-HRP antibody.

Localization of the HopZ1 proteins in plant cells was determined by confocal laser microscopy using HopZ1-YFP fusion proteins, which were transiently expressed in onion epidermal cells by particle bombardment using BioRad PDS1000/He Biolistic gene gun (BioRad Laboratories). After bombardment, onion tissues were incubated on Murashige-Skoog agar at $25^{\circ} \mathrm{C}$ in the dark for $24 \mathrm{~h}$. Cell plasmolysis was achieved by incubating the onion tissues in $30 \%$ sucrose solution for 10 min in order to obtain better visualization of the cell membrane. Transgenic onion cells were examined using Laser Scanning Microscope 510 equipped with Axio imager (Carl Zeiss Inc., Thornwood, NY, U.S.A.).

\section{Statistical analysis.}

Statistical analyses were performed using JMP 7.0 (SAS Institute Inc., Cary, NC, U.S.A.).

\section{ACKNOWLEDGMENTS}

H. Zhou and R. L. Morgan contributed equally to this work. We thank J. Lewis and P. Wang for providing plasmid constructs; Z. Yang, P. Wang, and M. B. Mudgett for providing plasmid vectors; X. Chen and S.-W. Ding for intellectual discussions and critically reading the manuscript; and I. Rajcan, K. Wang, and the United States Department of Agriculture (USDA) Soybean Germplasm Collection, USDA Agricultural Research Service (Urbana, IL, U.S.A.) for kindly providing soybean seed. This work is funded by University of California-Riverside start-up funds and a USDA-AES HATCH grant to W. Ma.

\section{LITERATURE CITED}

Abramovitch, R. B., and Martin, G. B. 2005. AvrPtoB: a bacterial type III effector that both elicits and suppresses programmed cell death associated with plant immunity. FEMS (Fed. Eur. Microbiol. Soc.) Microbiol. Lett. 245:1-8.

Alarcon-Chaidez, F. J., Penaloza-Vazquez, A., Ullrich, M., and Bender, C. L. 1999. Characterization of plasmids encoding the phytotoxin coronatine in Pseudomonas syringae. Plasmid 42:210-220.

Alfano, J. R., and Collmer, A. 1997. The type III (Hrp) secretion pathway of plant pathogenic bacteria: Trafficking harpins, Avr proteins, and death. J. Bacteriol. 179:5655-5662.

Alfano, J. R., and Collmer, A. 2004. Type III secretion system effector proteins: Double agents in bacterial disease and plant defense. Annu. Rev. Phytopathol. 42:385-414.

Allen, R. L., Bittner-Eddy, P. D., Grenville-Briggs, L. J., Meitz, J. C., Rehmany, A. P., Rose, L. E., and Beynon, J. L. 2004. Host-parasite coevolutionary conflict between Arabidopsis and downy mildew. Science 306:1957-1960.

Arnold, D. L., Jackson, R. W., Fillingham, A. J., Goss, S. C., Taylor, J. D., Mansfield, J. W., and Vivian, A. 2001. Highly conserved sequences flank avirulence genes: Isolation of novel avirulence genes from Pseudomonas syringae pv. pisi. Microbiology 147:1171-1182. 
Ashfield, T., Ong, L. E., Nobuta, K., Schneider, C. M., and Innes, R. W. 2004. Convergent evolution of disease resistance gene specificity in two flowering plant families. Plant Cell 16:309-318.

Barrett, A. J., and Rawlings, N. D. 2001. Evolutionary lines of cysteine peptidases. Biol. Chem. 382:727-733.

Bretz, J. R., and Hutcheson, S. W. 2004. Role of type III effector secretion during bacterial pathogenesis in another kingdom. Infect. Immun. 72:3697-3705.

Bretz, J. R., Mock, N. M., Charity, J. C., Zeyad, S., Baker, C. J., and Hutcheson, S. W. 2003. A translocated protein tyrosine phosphatase of Pseudomonas syringae pv. tomato DC3000 modulates plant defence response to infection. Mol. Microbiol. 49:389-400.

Budde, I. P., and Ullrich, M. S. 2000. Interactions of Pseudomonas syringae pv. glycinea with host and nonhost plants in relation to temperature and phytotoxin synthesis. Mol. Plant-Microbe Interact. 13:951-961.

Charity, J. C., Pak, K., Delwiche, C. F., and Hutcheson, S. W. 2003. Novel exchangeable effector loci associated with the Pseudomonas syringae hrp pathogenicity island: Evidence for integron-like assembly from transposed gene cassettes. Mol. Plant-Microbe Interact. 16:495-507.

Chisholm, S. T., Coaker, G., Day, B., and Staskawicz, B. J. 2006. Host-microbe interactions: Shaping the evolution of the plant immune response. Cell 124:803-814.

Dangl, J. L., and Jones, J. D. 2001. Plant pathogens and integrated defence responses to infection. Nature 411:826-833.

Dawkins, R., and Krebs, J. R. 1979. Arms races between and within species. Proc. R. Soc. Lond. B Biol. Sci. 205:489-511.

Deng, W. L., Rehm, A. H., Charkowski, A. O., Rojas, C. M., and Collmer, A. 2003. Pseudomonas syringae exchangeable effector loci: Sequence diversity in representative pathovars and virulence function in $P$. syringae pv. syringae B728a. J. Bacteriol. 185:2592-2602.

de Vries, J. S., Andriotis, V. M., Wu, A. J., and Rathjen, J. P. 2006. Tomato Pto encodes a functional N-myristoylation motif that is required for signal transduction in Nicotiana benthamiana. Plant J. 45:31-45.

Dodds, P. N., Lawrence, G. J., Catanzariti, A. M., Teh, T., Wang, C. I., Ayliffe, M. A., Kobe, B., and Ellis, J. G. 2006. Direct protein interaction underlies gene-for-gene specificity and coevolution of the flax resistance genes and flax rust avirulence genes. Proc. Natl. Acad. Sci. U.S.A. 103:8888-8893.

Espinosa, A., Guo, M., Tam, V. C., Fu, Z. Q., and Alfano, J. R. 2003. The Pseudomonas syringae type III-secreted protein HopPtoD2 possesses protein tyrosine phosphatase activity and suppresses programmed cell death in plants. Mol. Microbiol. 49:377-387.

Grant, S. R., Fisher, E. J., Chang, J. H., Mole, B. M., and Dangl, J. L. 2006. Subterfuge and manipulation: Type III effector proteins of phytopathogenic bacteria. Annu. Rev. Microbiol. 60:425-449.

Greenberg, J. T. 1997. Programmed cell death in plant-pathogen interactions. Annu. Rev. Plant Physiol. Plant Mol. Biol. 48:525-545.

Guttman, D. S., Vinatzer, B. A., Sarkar, S. F., Ranall, M. V., Kettler, G., and Greenberg, J. T. 2002. A functional screen for the type III (Hrp) secretome of the plant pathogen Pseudomonas syringae. Science 295:1722-1726.

Guttman, D. S., Gropp, S. J., Morgan, R. L., and Wang, P. W. 2006. Diversifying selection drives the evolution of the type III secretion system pilus of Pseudomonas syringae. Mol. Biol. Evol. 23:2342-2354.

He, S. Y., Nomura, K., and Whittam, T. S. 2004. Type III protein secretion mechanism in mammalian and plant pathogens. Biochim. Biophys. Acta 1694:181-206

Heath, M. C. 2000. Hypersensitive response-related death. Plant Mol. Biol. 44:321-334.

Herbers, K., Conrads-Strauch, J., and Bonas, U. 1992. Race-specificity of plant resistance to bacterial spot disease determined by repetitive motifs in a bacterial avirulence protein. Nature 356:172-174.

Hickman, M. J., Orser, C. S., Willis, D. K., Lindow, S. E., and Panopoulos, N. J. 1987. Molecular cloning and biological characterization of the recA gene from Pseudomonas syringae. J. Bacteriol. 169:2906-2910.

Hoang, T. T., Karkhoff-Schweizer, R. R., Kutchma, A. J., and Schweizer, H. P. 1998. A broad-host-range Flp-FRT recombination system for sitespecific excision of chromosomally-located DNA sequences: Application for isolation of unmarked Pseudomonas aeruginosa mutants. Gene 212:77-86.

Hotson, A., and Mudgett, M. B. 2004. Cysteine proteases in phytopathogenic bacteria: Identification of plant targets and activation of innate immunity. Curr. Opin. Plant Biol. 7:384-390.

Jamir, Y., Guo, M., Oh, H. S., Petnicki-Ocwieja, T., Chen, S., Tang, X., Dickman, M. B., Collmer, A., and Alfano, J. R. 2004. Identification of Pseudomonas syringae type III effectors that can suppress programmed cell death in plants and yeast. Plant J. 37:554-565.

Jelenska, J., Yao, N., Vinatzer, B. A., Wright, C. M., Brodsky, J. L., and Greenberg, J. T. 2007. A J domain virulence effector of Pseudomonas syringae remodels host chloroplasts and suppresses defenses. Curr. Biol. 17:499-508.
King, E. O., Ward, M. K., and Raney, D. E. 1954. Two simple media for the demonstration of pyocyanin and fluorescin. J. Lab. Clin. Med. 44:301-307.

Laemmli, U. K. 1970. Cleavage of structural proteins during the assembly of the head of bacteriophage T4. Nature 227:680-685.

Lewis, J. D., Abada, W., Ma, W., Guttman, D. S., and Desveaux, D. 2008. The HopZ family of Pseudomonas syringae type III effectors require myristoylation for virulence and avirulence functions in Arabidopsis. J. Bacteriol.

Lindeberg, M., Stavrinides, J., Chang, J. H., Alfano, J. R., Collmer, A., Dangl, J. L., Greenberg, J. T., Mansfield, J. W., and Guttman, D. S. 2005. Proposed guidelines for a unified nomenclature and phylogenetic analysis of type III Hop effector proteins in the plant pathogen Pseudomonas syringae. Mol. Plant-Microbe Interact. 18:275-282.

Linder, M. E., and Deschenes, R. J. 2007. Palmitoylation: Policing protein stability and traffic. Nat. Rev. Mol. Cell Biol. 8:74-84.

Ma, W., Dong, F. F., Stavrinides, J., and Guttman, D. S. 2006. Type III effector diversification via both pathoadaptation and horizontal transfer in response to a coevolutionary arms race. PLoS Genet. 2:e209.

Maurer-Stroh, S., and Eisenhaber, F. 2004. Myristoylation of viral and bacterial proteins. Trends Microbiol. 12:178-185.

McCann, H. C., and Guttman, D. S. 2008. Evolution of the type III secretion system and its effectors in plant-microbe interactions. New Phytol. 177:33-47.

Melotto, M., Underwood, W., Koczan, J., Nomura, K., and He, S. Y. 2006. Plant stomata function in innate immunity against bacterial invasion. Cell 126:969-980.

Mudgett, M. B., Chesnokova, O., Dahlbeck, D., Clark, E. T., Rossier, O., Bonas, U., and Staskawicz, B. J. 2000. Molecular signals required for type III secretion and translocation of the Xanthomonas campestris AvrBs2 protein to pepper plants. Proc. Natl. Acad. Sci. U.S.A. 97:13324-13329.

Mukherjee, S., Keitany, G., Li, Y., Wang, Y., Ball, H. L., Goldsmith, E. J., and Orth, K. 2006. Yersinia YopJ acetylates and inhibits kinase activation by blocking phosphorylation. Science 312:1211-1214.

Nimchuk, Z., Marois, E., Kjemtrup, S., Leister, R. T., Katagiri, F., and Dangl, J. L. 2000. Eukaryotic fatty acylation drives plasma membrane targeting and enhances function of several type III effector proteins from Pseudomonas syringae. Cell 101:353-363.

Orth, K., Palmer, L. E., Bao, Z. Q., Stewart, S., Rudolph, A. E., Bliska, J. B., and Dixon, J. E. 1999. Inhibition of the mitogen-activated protein kinase kinase superfamily by a Yersinia effector. Science 285:19201923.

Orth, K., Xu, Z., Mudgett, M. B., Bao, Z. Q., Palmer, L. E., Bliska, J. B. Mangel, W. F., Staskawicz, B., and Dixon, J. E. 2000. Disruption of signaling by Yersinia effector YopJ, a ubiquitin-like protein protease. Science 290:1594-1597.

Pitman, A. R., Jackson, R. W., Mansfield, J. W., Kaitell, V., Thwaites, R., and Arnold, D. L. 2005. Exposure to host resistance mechanisms drives evolution of bacterial virulence in plants. Curr. Biol. 15:2230-2235.

Resh, M. D. 1999. Fatty acylation of proteins: New insights into membrane targeting of myristoylated and palmitoylated proteins. Biochim. Biophys. Acta 1451:1-16.

Riviere, M. P., Marais, A., Ponchet, M., Willats, W., and Galiana, E. 2008. Silencing of acidic pathogenesis-related PR-1 genes increases extracellular beta-(1->3)-glucanase activity at the onset of tobacco defence reactions. J. Exp. Bot. 59:1225-1239.

Robertson, A. E., Wechter, W. P., Denny, T. P., Fortnum, B. A., and Kluepfel, D. A. 2004. Relationship between avirulence gene (avrA) diversity in Ralstonia solanacearum and bacterial wilt incidence. Mol. Plant-Microbe Interact. 17:1376-1384.

Rohmer, L., Guttman, D. S., and Dangl, J. L. 2004. Diverse evolutionary mechanisms shape the type III effector virulence factor repertoire in the plant pathogen Pseudomonas syringae. Genetics 167:1341-1360.

Salter, M. G., and Conlon, H. E. 2007. Extraction of plant RNA. Methods Mol. Biol. 362:309-314.

Sambrook, J., and Russell, D. W. 2001. Molecular Cloning: A Laboratory Manual. Cold Spring Harbor Laboratory Press, Cold Spring Harbor, NY, U.S.A.

Sarkar, S. F., and Guttman, D. S. 2004. Evolution of the core genome of Pseudomonas syringae, a highly clonal, endemic plant pathogen. Appl. Environ. Microbiol. 70:1999-2012.

Shan, L., Thara, V. K., Martin, G. B., Zhou, J. M., and Tang, X. 2000. The pseudomonas AvrPto protein is differentially recognized by tomato and tobacco and is localized to the plant plasma membrane. Plant Cell $12: 2323-2338$.

Sokurenko, E. V., Chesnokova, V., Dykhuizen, D. E., Ofek, I., Wu, X. R. Krogfelt, K. A., Struve, C., Schembri, M. A., and Hasty, D. L. 1998. Pathogenic adaptation of Escherichia coli by natural variation of the FimH adhesin. Proc. Natl. Acad. Sci. U.S.A. 95:8922-8926. 
Sokurenko, E. V., Hasty, D. L., and Dykhuizen, D. E. 1999. Pathoadaptive mutations: Gene loss and variation in bacterial pathogens. Trends $\mathrm{Mi}$ crobiol. 7:191-195.

Stahl, E. A., and Bishop, J. G. 2000. Plant-pathogen arms races at the molecular level. Curr. Opin. Plant Biol. 3:299-304.

Sundin, G. W., Mayfield, C. T., Zhao, Y., Gunasekera, T. S., Foster, G. L., and Ullrich, M. S. 2004. Complete nucleotide sequence and analysis of pPSR1 (72,601 bp), a pPT23A-family plasmid from Pseudomonas syringae pv. syringae A2. Mol. Genet. Genomics 270:462-476.

Szurek, B., Marois, E., Bonas, U., and Van den Ackerveken, G. 2001. Eukaryotic features of the Xanthomonas type III effector AvrBs3: Protein domains involved in transcriptional activation and the interaction with nuclear import receptors from pepper. Plant J. 26:523-534.

Szurek, B., Rossier, O., Hause, G., and Bonas, U. 2002. Type III-dependent translocation of the Xanthomonas AvrBs3 protein into the plant cell. Mol. Microbiol. 46:13-23.

Thieme, F., Szczesny, R., Urban, A., Kirchner, O., Hause, G., and Bonas, U. 2007. New type III effectors from Xanthomonas campestris pv. vesicatoria trigger plant reactions dependent on a conserved N-myristoylation motif. Mol. Plant-Microbe Interact. 20:1250-1261.

Trevors, J. 1986. Plasmid curing in bacteria. FEMS (Fed. Eur. Microbiol. Soc.) Microbiol. Rev. 32:149-157.

Van der Hoorn, R. A., De Wit, P. J., and Joosten, M. H. 2002. Balancing selection favors guarding resistance proteins. Trends Plant Sci. 7:67-71.

Van Larebeke, N., Engler, G., Holsters, M., Van den Elsacker, S., Zaenen,
I., Schilperoort, R. A., and Schell, J. 1974. Large plasmid in Agrobacterium tumefaciens essential for crown gall-inducing ability. Nature 252:169-170.

Vinatzer, B. A., Teitzel, G. M., Lee, M. W., Jelenska, J., Hotton, S., Fairfax, K., Jenrette, J., and Greenberg, J. T. 2006. The type III effector repertoire of Pseudomonas syringae pv. syringae B728a and its role in survival and disease on host and non-host plants. Mol. Microbiol. 62:26-44.

von Arnim, A. G., and Deng, X. W. 1994. Light inactivation of Arabidopsis photomorphogenic repressor COP1 involves a cell-specific regulation of its nucleocytoplasmic partitioning. Cell 79:1035-1045.

von Arnim, A. G., Deng, X. W., and Stacey, M. G. 1998. Cloning vectors for the expression of green fluorescent protein fusion proteins in transgenic plants. Gene 221:35-43.

West, S. E., Schweizer, H. P., Dall, C., Sample, A. K., and RunyenJanecky, L. J. 1994. Construction of improved Escherichia-Pseudomonas shuttle vectors derived from pUC18/19 and sequence of the region required for their replication in Pseudomonas aeruginosa. Gene 148:81-86.

Win, J., Morgan, W., Bos, J., Krasileva, K. V., Cano, L. M., ChaparroGarcia, A., Ammar, R., Staskawicz, B. J., and Kamoun, S. 2007. Adaptive evolution has targeted the C-terminal domain of the RXLR effectors of plant pathogenic oomycetes. Plant Cell 19:2349-2369.

Yang, Y., and Gabriel, D. W. 1995. Xanthomonas avirulence/pathogenicity gene family encodes functional plant nuclear targeting signals. Mol. Plant-Microbe Interact. 8:627-631. 